\title{
Regulated Viral BDNF Delivery in Combination with Schwann Cells Promotes Axonal Regeneration through Capillary Alginate Hydrogels after Spinal Cord Injury
}

\section{Shengwen Liu ${ }^{1,2}$, Beatrice Sandner ${ }^{1}$, Thomas Schackel ${ }^{1}$, LaShae Nicholson ${ }^{1}$, Abdelwahed Chtarto $^{4}$, Liliane Tenenbaum ${ }^{5}$, Radhika Puttagunta ${ }^{1}$, Rainer Müller ${ }^{3}$, Norbert Weidner ${ }^{1}$ and Armin Blesch ${ }^{1,6, *}$}

\footnotetext{
${ }^{1}$ Spinal Cord Injury Center, Heidelberg University Hospital, Heidelberg, Germany

${ }^{2}$ Department of Neurosurgery, Tongji Hospital, Tongji Medical College, Huazhong University of Science and Technology, Wuhan, P.R. China

${ }^{3}$ Department of Physical and Theoretical Chemistry, University of Regensburg, Regensburg, Germany

${ }^{4}$ Experimental Neurosurgery Laboratory and I.R.I.B.H.M., Université Libre de Bruxelles (ULB), Brussels, Belgium

${ }^{5}$ Department of Clinical Neurosciences, University Hospital of Lausanne, Lausanne, Switzerland ${ }^{6}$ Stark Neurosciences Research Institute, Indiana University School of Medicine, Dept. of Neurological Surgery and Goodman Campbell Brain and Spine, Indianapolis, USA
}

Short Title: Alginate, Schwann cells and BDNF after Spinal Cord Injury

\section{Text Pages: $21 \quad$ Figures: $8 \quad$ Suppl. Figures: 4}

Abstract: 216 words Introduction: 672 words Discussion/Conclusion: 1298 words

\begin{abstract}
*Correspondence to:
Armin Blesch, Ph.D.

Stark Neuroscience Research Institute

Indiana University School of Medicine

Dept. of Neurological Surgery and Goodman Campbell Brain and Spine

320 W. 15 th St.

Indianapolis, IN 46202

Email: ablesch@iupui.edu

Phone: $317-278-5854$
\end{abstract}

This is the author's manuscript of the article published in final edited form as:

Liu, S., Sandner, B., Schackel, T., Nicholson, L., Chtarto, A., Tenenbaum, L., ... Blesch, A. (2017). Regulated Viral BDNF Delivery in Combination with Schwann Cells Promotes Axonal Regeneration through Capillary Alginate Hydrogels after Spinal Cord Injury. Acta Biomaterialia. https://doi.org/10.1016/j.actbio.2017.07.024 


\begin{abstract}
:
Grafting of cell-seeded alginate capillary hydrogels into a spinal cord lesion site provides an axonal bridge while physically directing regenerating axonal growth in a linear pattern.

However, without an additional growth stimulus, bridging axons fail to extend into the distal host spinal cord. Here we examined whether a combinatory strategy would support regeneration of descending axons across a cervical (C5) lateral hemisection lesion in the rat spinal cord.

Following spinal cord transections, Schwann cell (SC)-seeded alginate hydrogels were grafted to the lesion site and AAV5 expressing brain-derived neurotrophic factor (BDNF) under control of a tetracycline-regulated promoter was injected caudally. In addition, we examined whether SC injection into the caudal spinal parenchyma would further enhance regeneration of descending axons to re-enter the host spinal cord. Our data show that both serotonergic and descending axons traced by biotinylated dextran amine (BDA) extend throughout the scaffolds. The number of regenerating axons is significantly increased when caudal BDNF expression is activated and transient BDNF delivery is able to sustain axons after gene expression is switched off. Descending axons are confined to the caudal graft/host interface even with continuous BDNF expression for 8 weeks. Only with a caudal injection of SCs, a pathway facilitating axonal regeneration through the host/graft interface is generated allowing axons to successfully re-enter the caudal spinal cord.
\end{abstract}

Keywords: Alginate hydrogel, spinal cord injury, Schwann cells, brain-derived neurotrophic factor, axonal regeneration, regulated gene expression, biomaterial, AAV5 
Liu et al.

\section{Introduction}

Axonal regeneration after injury of the mammalian spinal cord is very limited. This is due to an inhibitory microenvironment, cavitation and fibroglial scarring around the lesion site, an insufficient intrinsic growth capacity of adult neurons in the central nervous system (CNS), as well as a lack of suitable growth substrates and growth-stimulating factors [1,2]. Several strategies including grafting of cells and/or biomaterials [3], delivery of growth factors and degradation of inhibitory matrix molecules [4], activation of an intrinsic growth program [5], and stabilization of growth cones and axonal cytoskeleton [6] have aimed to overcome these impediments. Of these approaches, biomaterials that can not only fill a lesion cavity, but can also provide a substrate for cellular grafting, physical guidance of regenerating axons and a vehicle for drug delivery are highly promising for cellular and molecular regenerative therapies [7].

We have previously shown that anisotropic capillary hydrogels made from alginate, a natural biopolymer from the cell walls of brown algae and widely used in the food and pharmaceutical industry, are able to physically guide axons in vitro [8-10]. In the injured spinal cord, linear axonal growth in a rostro-caudal direction is enhanced when hydrogels are seeded with bone marrow stromal cells (BMSCs) and further amplified when BMSCs are genetically modified to overexpress the neurotrophin brain-derived neurotrophic factor (BDNF). However, axons fail to extend beyond the lesion site $[11,12]$. The continuous expression of BDNF by cells within the scaffold may saturate the receptors of regenerating axons, which therefore fail to extend beyond the graft into the host tissue with lower BDNF levels. In addition, the limited integration of BMSCs into the spinal cord, and fibroglial scarring around the implant confine regenerating axons to the lesion site [11]. To address these issues, we explored Schwann cells as a more compatible cell candidate, along with distal growth factor delivery to chemotropically attract bridging axons into the host tissue.

Schwann cells (SCs) support axonal growth in the injured spinal cord and are currently examined in clinical trials as an autologous cellular graft [13]. After transplantation, SCs can myelinate re-growing and spared, demyelinated axons to support their maintenance and elongation [14-16]. In addition, SCs secrete neurotrophic factors including nerve growth factor (NGF), neurotrophin-3 (NT-3), glial cell line-derived neurotrophic factor (GDNF) and ciliary neurotrophic factor (CNTF) [17-19] as well as extracellular matrix molecules (e.g. laminin, fibronectin and collagen) [20,21], which are known to protect spared tissues and facilitate axonal growth. Furthermore, several studies have demonstrated that SC grafts may serve as bridges within the lesion and intermingle with astrocytic processes, making the graft/host interface more permissive for axonal extension [4, 22].

Brain-derived neurotrophic factor (BDNF) is one of the best characterized neurotrophins promoting neural protection and axonal regeneration after SCI [23-26]. Increasing BDNF levels in the host parenchyma by overexpression or ectopic delivery can overcome the inhibitory effects of proteoglycans in the scar and stimulate axonal growth beyond the lesion edge [27, 28]. 
Transient BDNF delivery by genetically modified fibroblasts can sustain regenerated axons within the lesion site [29], however continuous BDNF overexpression may induce spasticity-like symptoms and deterioration of functional outcomes [30,31]. A regulated delivery system is therefore needed. Tetracycline-regulated expression systems containing a tetracycline (Tet)-responsive promoter and transactivator have been used extensively to stringently control the expression of target genes [32, 33]. Two systems (Tet-off and Tet-on) have been described depending on whether gene expression is downregulated or upregulated in the presence of Tet. For clinical translation requiring transient gene expression, the Tet-on system has the major advantage that administration of Tet is only required during the period of desired gene expression [29].

In the present study, we applied a combinatorial approach of alginate hydrogels seeded with syngeneic SCs and a distal gradient of tet-regulated viral BDNF expression to promote descending axonal growth through the lesion. Our data show that the number of regenerating axons is enhanced by transient viral neurotrophin expression, and in combination with SC injection into the host parenchyma, descending axons extend across the hydrogel into the distal spinal parenchyma.

\section{Materials and Methods}

\subsection{Production of capillary alginate hydrogels}

Alginate hydrogels with longitudinally aligned circular capillaries were prepared as previously described $[8,10,11]$. Ultrapure sodium alginate (UP MVG, Novamatrix FMC) with medium viscosity $(>200 \mathrm{mPa} \cdot \mathrm{s})$ and $70 \%$ guluronic acid content was dissolved in ion-free water (Millipore) at a concentration of $2 \%(\mathrm{w} / \mathrm{w})$ before being filtered through a $0.2 \mu \mathrm{m}$ polyethersulfone membrane (VWR). The alginate solution $(65 \mathrm{~g})$ was transferred into an anisotropic hydrogel by covering it with $20 \mathrm{ml}$ of $1 \mathrm{M} \mathrm{Zn}\left(\mathrm{NO}_{3}\right)_{2}$ in an anodized cylindrical aluminum mold (diameter 5cm; Schuett-Biotec) and a minimum diffusion time of $36 \mathrm{~h}$. The gel was rinsed with deionized water to remove excessive electrolytes and the top $5 \mathrm{~mm}$ layer without capillary structures was cut off to obtain a $15 \mathrm{~mm}$ thick gel block. For chemical cross-linking, the gel block was dehydrated in increasing concentrations of acetone $(25 \%, 50 \%, 75 \%, 100 \%)$ followed by dry acetone containing $0.1 \mathrm{M}$ hexamethylene-di-isocyanate (HDI; VWR). Fixed gel blocks were rinsed in $0.1 \mathrm{M} \mathrm{HCl}$ to exchange cross-linking $\mathrm{Zn}^{2+}$ cations and washed in purified water until a neutral $\mathrm{pH}$ was reached. Afterwards, the gel was cut into $2 \times 2 \times 1.3 \mathrm{~mm}$ cubes (length of capillaries: $2 \mathrm{~mm}$ ) using a vibratome (Leica) and stored in 70\% ethanol. Each scaffold was visualized under light microscopy (Olympus) to analyze dimension and density of capillaries. Only blocks with evenly distributed and straight capillaries parallel to the long axis of the scaffolds were selected for in vivo experiments. One day before implantation, alginate hydrogel scaffolds were transferred into Dulbecco's phosphate-buffered saline (D'PBS) for washing and stored overnight. The scaffolds used for implantation showed longitudinally aligned and evenly distributed capillaries at a density of $61 \pm 4$ channels $/ \mathrm{mm}^{2}$ with a capillary diameter of $64.4 \pm 6.2$ $\mu \mathrm{m}$ (Fig. 1A) and a wall/channel ratio of approximately 4:1. 


\subsection{Production and characterization of regulated adeno-associated viral (AAV) vectors}

The basic vector rAAV-rtTA-GFP carrying a tetracycline (Tet)-regulated bi-directional promoter ( pTet $_{\text {bidi }} \mathrm{ON}$ ) and the coding sequence for enhanced green fluorescence protein (GFP) has been described previously [34]. To further improve this vector, the original tet-responsive transactivator (rtTA) sequence [35] was replaced by rtTAV16, a mutated rtTA with improved doxycyline-sensitivity [36]. To obtain a BDNF Tet-regulated vector, the plasmid was digested with AgeI/NotI (Biolabs) to remove the GFP cDNA and an AgeI/NotI fragment containing the human BDNF cDNA was cloned into this site. For initial in vitro testing, plasmids were transfected into $293 \mathrm{~T}$ cells using a calcium-phosphate transfection. Cells were treated with 1 $\mu \mathrm{g} / \mathrm{ml}$ doxycycline (Dox; Sigma-Aldrich) for $24 \mathrm{~h}$ and the culture medium was collected for analysis of BDNF levels. The cells were fixed with $4 \%$ paraformaldehyde (PFA) and incubated with $0.25 \mu \mathrm{g} / \mathrm{ml}$ 4,6-diamidino-2-phenylndole (DAPI; Sigma Aldrich) to quantify the number of GFP expressing cells under a fluorescence microscope (IX81; Olympus).

For in vivo experiments, the rAAV-rtTAV16 vectors were packaged into recombinant adeno-associated virus serotype 5 (rAAV5) capsids by the Gene Therapy Center Vector Core (University of North Carolina, USA). AAV5 has previously been shown to allow for more widespread expression in brain and spinal cord [37]. Viral titers as determined by quantitative polymerase chain reaction (qPCR) were: $1.5 \times 10^{12} \mathrm{vg} / \mathrm{ml}$ for $\mathrm{rAAV} 5-\mathrm{GFP}$ (rAAV-rtTAV16-GFP), $2.3 \times 10^{12} \mathrm{vg} / \mathrm{ml}$ for rAAV5-BDNF (rAAV-rtTAV16-BDNF).

\subsection{Primary cultures of SCs}

Highly purified SCs were prepared from sciatic nerves of wild-type (WT) Fischer 344 rats (Charles River) or GFP-transgenic Fischer 344 rats (F344-Tg(UBC-EGFP) F455Rrrc; Rat Resource and Research Center, Columbia, MO). Nerves were cut into $1 \mathrm{~mm}$-long explants and cultured with Dulbecco's modified Eagle's medium (DMEM; Life Technologies) containing 10\% fetal bovine serum (FBS) and $100 \mathrm{U} / \mathrm{ml}$ antibiotics (penicillin and streptomycin, Gibco). When migratory cells (primarily fibroblasts) around the explants reached confluence after approximately one week in culture, explants were transferred into a new dish with fresh cell culture medium. After 5-6 weeks, nerve explants were dissociated by $1.25 \mathrm{U} / \mathrm{ml}$ dispase (Worthington) and $0.05 \%$ collagenase XI (Sigma Aldrich) and replated in DMEM containing $10 \% \mathrm{FBS}, 20 \mu \mathrm{g} / \mathrm{ml}$ pituitary extract and $2 \mu \mathrm{M}$ forskolin (Sigma-Aldrich). Cells were passaged twice before transplantation. The purity of SCs evaluated by immunolabeling for the low affinity neurotrophin receptor p75 (mAB192MB hybridoma supernatants) and DAPI was 96-98\%.

\subsection{Animal subjects and doxycycline treatment}

Adult female Fischer 344 rats (total n=73) weighing 150-200g were used in this study. National guidelines and the European Union Directive (2010/63/EU) were strictly followed for surgical procedures and animal care. Animals were housed in standard cages and had free access to water and food. Two days prior to surgery, animals were randomly divided into groups that were either treated with Dox in the drinking water (+Dox; $2 \mathrm{mg} / \mathrm{ml}$ in $5 \%$ sucrose) for the time indicated in 
Table 1, in some cases followed by withdrawal of Dox. Control animals received 5\% sucrose (-Dox) only throughout the experiment.

\subsection{Surgical procedures}

Animals were deeply anesthetized by intramuscular injection of a cocktail $(2.5 \mathrm{ml} / \mathrm{kg})$ of ketamine (62.5 mg/kg; Bremer Pharma), xylazine $(3.175 \mathrm{mg} / \mathrm{kg}$; Ecuphar) and acepromazine (0.625 mg/kg; Ceva). A laminectomy was performed at vertebra C4 (cervical spinal level C5), followed by a longitudinal incision of the dura to create a cervical spinal cord hemisection for hydrogel transplantation. After two lateral subdural spinal incisions spaced 1.5-2 mm apart, a block of spinal cord tissue at C5 was removed by alternately using micro-scissors and micro-aspiration (Fig. 1). Immediately prior to the transplantation, the scaffolds were pre-loaded with $2-3 \mu \mathrm{l}\left(1 \times 10^{5}\right.$ cells/ $\left.\mu \mathrm{l}\right)$ of SCs suspended in $1 \mathrm{mg} / \mathrm{ml}$ glucose in PBS and derived from WT or GFP-transgenic animals (Table 1). Scaffolds were carefully implanted into the lesion cavity ensuring that the capillary direction was parallel to the spinal cord axis and the scaffold closely embedded into the surrounding tissue. An agarose film $(2 \times 3 \mathrm{~mm})$ was placed over the scaffold and a mixture of $2 \mu \mathrm{l}$ fibrinogen $(100 \mathrm{mg} / \mathrm{ml}$; Sigma Aldrich) and $2 \mu \mathrm{l}$ thrombin $(400 \mathrm{U} / \mathrm{ml}$; Sigma Aldrich) was used to cover the dural opening. AAV vectors $(8 \mu \mathrm{l})$ were injected via a pulled glass capillary into the ipsilateral spinal cord 4 or $6 \mathrm{~mm}$ caudal to the lesion, $1 \mathrm{~mm}$ lateral to the midline, at a depth of $1.5 \mathrm{~mm}$. This was based on a preliminary experiment, which indicated that rAAV5-GFP diffuses 4-6 mm away from the injection site in the intact spinal cord. Injections were performed at a speed of $0.5 \mu \mathrm{l} / \mathrm{min}$ using a Picospritzer (Parker Hannifin). In one group of animals, GFP-transgenic SCs $\left(1 \times 10^{5}\right.$ cells in $\left.1 \mu \mathrm{l}\right)$ were also injected into the spinal cord $1 \mathrm{~mm}$ caudal to the lesion (Table 1). After each injection, the glass capillary was left in place for 2 min and slowly withdrawn. Muscles were repositioned, sutured and the skin was stapled. To label descending propriospinal axons and possibly other axons of passage, $1 \mu \mathrm{l}$ of $10 \%$ biotinylated dextran amine (BDA; MW 10,000kDa; Life Technologies) was injected at a depth of $1.5 \mathrm{~mm}, 1 \mathrm{~mm}$ lateral to the midline between $\mathrm{C} 1$ and $\mathrm{C} 2$ ipsilaterally to the lesion 3 or 7 weeks later (one week before sacrifice). For post-operative treatment, all animals were injected subcutaneously twice a day with buprenorphine (30-40 $\mu \mathrm{g} / \mathrm{kg}$, Temgesic, Reckitt Benckiser) for two days and ampicillin (150 mg/kg, Ratiopharm) for 5-7 days to prevent infections. Carprofen (4-5 mg/kg, Rimadyl, Pfizer) was injected subcutaneously beyond 2 days post-surgery for further pain relieve as needed. All animals were fed with $2 \mathrm{ml}$ high-energy nutrition drink (Fresubin, Fresenius Kabi) three times per day until their body weight started to increase. Dox $(5 \mathrm{mg} / \mathrm{ml})$ was mixed in the drink of designated groups.

\subsection{Characterization of BDNF expression in vivo}

Four weeks after grafting and virus injection, animals were deeply anesthetized and transcardially perfused with $50 \mathrm{ml}$ of ice-cold $0.1 \mathrm{M}$ phosphate-buffered saline (PBS). The spinal cord ipsilateral to lesion as well as the biomaterial implants were carefully removed and immediately frozen at $-80^{\circ} \mathrm{C}$ for further processing. In a pilot experiment, an $8 \mathrm{~mm}$ long segment adjacent to the lesion was used to assess the total amount of BDNF in the host spinal cord after 
AAV5 injection (Table 1: GFP-Dox, $n=3$; GFP +Dox, n=3; BDNF -Dox, n=3; BDNF +Dox, $\mathrm{n}=4)$. For a more detailed analysis of BDNF levels, spinal cords collected from animals injected with rAAV5-BDNF and treated with Dox $(n=6)$ or without Dox $(n=4)$ were cut into $100 \mu \mathrm{m}$ thick coronal sections on a cryostat (Zeiss) and consecutive series of 10 sections were pooled into $1 \mathrm{~mm}$ segments. BDNF levels were also measured within the scaffold in all of the animals described above.

Samples were weighed before sonication in $40 \mu \mathrm{l} / \mathrm{mg}$ lysis buffer (PBS with $0.25 \%$ Triton $\mathrm{X}-100,5 \mathrm{mM}$ EDTA, $0.5 \% \mathrm{BSA}, 1 \mathrm{mM}$ PMSF, and $1 \mu \mathrm{l} / \mathrm{ml}$ aprotinin). After centrifugation at $14,000 \mathrm{rpm}$ at $4^{\circ} \mathrm{C}$ for $10 \mathrm{~min}$, supernatants were collected for BDNF ELISA as previously described [29]. Briefly, rabbit anti-BDNF antibody (1:2000; Acris) was coated in 96-well plates while normal rabbit IgG was used as control. After 4 washes, plates were blocked with 3\% bovine serum albumin (BSA; Sigma Aldrich) and diluted spinal cord tissue lysates were added. Serially diluted recombinant human BDNF (Biochrom) was used as standard. Plates were incubated overnight at $4{ }^{\circ} \mathrm{C}$, followed by 4 washes and overnight incubation with chicken anti-BDNF antibody (1:2500; Promega) under the same conditions. Plates were washed and incubated with anti-chicken IgY coupled to horseradish peroxidase (HRP, 1:1000; Promega) overnight. Additional washes were performed and o-phenylenediamine $(0.5 \mathrm{mg} / \mathrm{ml}$; Sigma-Aldrich) was added as substrate for HRP detection. After $15 \mathrm{~min}$, the reaction was terminated with $10 \% \mathrm{H}_{2} \mathrm{SO}_{4}$ and the absorption was detected by a spectrophotometer (Tecan) at $490 \mathrm{~nm}$ wavelength. Absorption values of control wells coated with normal IgG were subtracted from wells coated with anti-BDNF antibody to exclude nonspecific binding. Diluted cell culture supernatants were analyzed using the same methods.

\subsection{Tissue preparation and immunohistochemistry}

Animals were deeply anesthetized and transcardially perfused with $100 \mathrm{ml}$ ice-cold PBS, followed by $250 \mathrm{ml}$ ice-cold $4 \%$ paraformaldehyde (PFA) in $0.1 \mathrm{M}$ phosphate buffer (PB). Brains and spinal cords were dissected, post-fixed in PFA for 1 hour and cryoprotected in $30 \%$ sucrose in $0.1 \mathrm{M} \mathrm{PB}$ at $4^{\circ} \mathrm{C}$. Horizontal sections were cut on a cryostat at $30 \mu \mathrm{m}$ intervals from a $2.5 \mathrm{~cm}$ long block of spinal cord tissue centered around the grafts. Every $15^{\text {th }}$ section was directly mounted onto the same glass slide for immunolabeling.

For immunolabeling, sections were rinsed in tris-buffered saline (TBS) and blocked with 5\% donkey serum / $0.25 \%$ Triton X-100 in TBS. Sections were incubated with different combinations of the following antibodies: rabbit anti-GFP (1:1000; Life Technologies), mouse anti-GFP (1:2000; Life Technologies), goat anti-GFP (1:1000; Rockland), guinea pig anti-glial fibrillary acidic protein (GFAP, 1:500; Progen), rabbit anti-GFAP (1:1000; Dako), goat anti-Olig2 (1:500; Santa Cruz), mouse anti-NeuN (1:200; Millipore), mouse anti- $\beta$ III-tubulin (1:750; Promega) and rabbit anti-5-hydroxytryptamine (5-HT, 1:2000; Immunostar), streptavidin-Alexa 594 (to detect the anterograde tracer BDA, 1:500; Jackson Immuno Research). On the following day, secondary antibodies made in donkey including anti-rabbit and anti-mouse IgG coupled to Alexa 488, or Alexa 594 (all 1:300; Invitrogen) and anti-guinea pig IgG coupled to Cy5 (1:500; Jackson Immuno Research) were used and co-incubated with 0.25 
$\mu \mathrm{g} / \mathrm{ml}$ DAPI to visualize nuclei. Sections were dried and coverslipped with Fluoromount $\mathrm{G}$ (Southern Biotech). Sections were imaged using a XC30 camera connected to a BX53 microscope (Olympus) or a FluoView 1000 confocal microscope (BX61; Olympus).

To detect BDA-labeled axons in light level, sections were incubated with $0.6 \%$ hydrogen peroxide in methanol to block endogenous peroxidase activity for $30 \mathrm{~min}$ at RT and washed in TBS. Sections were incubated overnight at $4^{\circ} \mathrm{C}$ with avidin-biotinylated peroxidase complex in TBS (Elite kit, 1:100; Vector Laboratories). After several washes, sections were maintained in a solution of diaminobenzidine with nickel chloride and hydrogen peroxide (Peroxidase substrate kit; Vector Laboratories) for 5-10 min before additional washing at RT. Sections were dehydrated and coverslipped with Cytoseal 60 (Thermo Fisher Scientific).

\subsection{Quantification of axon profiles within and beyond the scaffold}

The number of axons within the scaffold capillaries was counted in 2 out of 14 series by a person blinded to treatment conditions. Immunolabeled axons in all capillaries crossing imaginary lines perpendicular to the rostral-caudal axis of the hydrogel at $100 \mu \mathrm{m}, 500 \mu \mathrm{m}$ and $1000 \mu \mathrm{m}$ from the rostral edge as well as $100 \mu \mathrm{m}$ and $500 \mu \mathrm{m}$ from the caudal edge of each section were counted at $20 \times$ magnification to quantify $\beta$ III-tubulin labeled axons. The number of axons per $\mathrm{mm}^{2}$ hydrogel was calculated using the following equation:

$$
\mathrm{N}=\frac{\sum \text { axons }}{1,000,000 * \text { section thickness }(\mu \mathrm{m}) * \sum \text { width of the hydrogel at specific distance }(\mu \mathrm{m})} \text {. }
$$

BDA and 5-HT-labeled axons in the hydrogel were quantified in one out of 14 serial sections. The maximum number of axons observed at any distance in every channel was quantified separately in the rostral and caudal half of the hydrogel and divided by the total number of channels present in the section. Axons extending in the same channel were only counted once. The number of axons per channel was averaged for each animal and means of each group were used for statistical comparison. BDA-labeled axonal profiles in the ipsilateral host tissue crossing imaginary lines placed perpendicular to the longitudinal axis of the spinal cord caudal to the hydrogel edge at 100, 200, 400, 600, 800, 1000 and $1200 \mu \mathrm{m}$ were also counted in 2 out of 14 serial sections.

\subsection{Statistics}

All data are presented as mean \pm standard error (SEM) and GraphPad Prism 5.01 software was used for all statistical analyses. Comparisons between groups were made using unpaired Student's t-test or non-parametric analysis for data not normally distributed (Kruskal-Wallis test followed by Dunn's test). One-way ANOVA with Tukey's post hoc analysis or two-way ANOVA with Bonferroni post hoc tests were used for multiple comparisons. A significance criterion of $p<0.05$ was used.

\section{Results}

\subsection{Integration of SC-seeded alginate hydrogels in the host spinal cord}


For hydrogels to be suitable as implant in the injured spinal cord, they must integrate into host tissue without excessive scarring, maintain its integrity over the period of axonal regeneration and allow for sufficient diffusion of nutrients to support cell survival. The architecture of alginate hydrogels remained stable at 4 weeks (Fig. 2A-C) and 8 weeks (Suppl. Fig 4, Fig. 8) post implantation into a cervical hemisection, the longest time point examined. Scaffolds filled the spinal cord lesion site, numerous grafted GFP-labeled SCs survived within the channels and the adjacent tissue, integrating the hydrogel at the rostral and caudal ends of the lesion with the host spinal cord (Fig. 2C-F). GFAP-labeled astrocytes showed mild hypercellularity around the hydrogel with rare cavitation between the scaffold and the host tissue.

\subsection{Characterization of regulated GFP and BDNF expression in vitro and in vivo}

To characterize the tet-regulated plasmids, we first transfected 293T cells with rAAV-rtTAV16-GFP or -BDNF plasmid (Suppl. Fig. 1A). A significantly larger number of $\mathrm{GFP}^{+}$cells was observed in the group transfected with rAAV-rtTAV16-GFP (henceforth referred to as rAAV5-GFP) and treated with Dox (Suppl. Fig. 1B-F) when compared to cells transfected with the same plasmid without Dox treatment. After transfection with rAAV-rtTAV16-BDNF (henceforth referred to as rAAV5-BDNF), BDNF expression was upregulated 26-fold in cells receiving Dox in the culture medium $(3.31 \pm 0.06 \mathrm{ng} / \mathrm{ml}$ per $24 \mathrm{~h})$ compared to cells that did not receive Dox. No BDNF was detected in cells transfected with the rAAV5-GFP control plasmid (Suppl. Fig. 1G).

Based on these results, animals were injected with rAAV5-GFP $4 \mathrm{~mm}$ caudal to the hydrogel implant and continuously received Dox $(2 \mathrm{mg} / \mathrm{ml})$ or only $5 \%$ sucrose in the drinking water for 4 weeks. Only a limited number of cells confined primarily to the virus injection site showed GFP fluorescence in animals that were not treated with Dox (Fig. 3A, C). In contrast, Dox-treated animals exhibited strong GFP fluorescence in the spinal cord ipsilateral to the lesion, which extended from the injection site to the graft/host border as well as $\sim 5 \mathrm{~mm}$ caudal from the injection site (in total $\sim 9 \mathrm{~mm}$ from the hydrogel) (Fig. 3B, D, E). Based on the morphology of GFP-labeled cells and double labeling with neuronal, astroglial and oligodendroglial markers, infected cells were primarily glia, but also host neurons (Suppl. Fig. 2). No GFP-labeled cells were observed within the channels of either rAAV5-GFP injected groups.

Measuring overall BDNF levels by ELISA in an $8 \mathrm{~mm}$ ipsilateral spinal cord segment caudal to the lesion in animals injected with rAAV5-BDNF showed similar results. The highest levels were measured in animals that received Dox. In the absence of Dox, BDNF expression in animals injected with rAAV5-BDNF showed a minor increase, however did not significantly differ from BDNF levels in animals injected with rAAV5-GFP (Fig. 3F). BDNF levels in the alginate hydrogel were only slightly elevated in subjects receiving rAAV5-BDNF and Dox treatment with no significant difference between all groups (Fig. 3G). Given that animals injected with GFP virus did not indicate any GFP-labeled cells within the graft, it is likely that any BDNF in the alginate is derived from Schwann cells and BDNF diffusion from the adjacent host tissue. 
Importantly, the spread of rAAV5-BDNF established a neurotrophic gradient within the spinal cord. BDNF levels in the first $9 \mathrm{~mm}$ caudal to the graft were significantly increased in animals after Dox treatment. The peak level of BDNF was detected directly at the vector injection site, with BDNF levels decreasing in rostral and caudal direction, although a slight increase in BDNF levels was observed close to the lesion. In the absence of Dox, animals showed a mild, but insignificant increase of BDNF at the injection site and at the graft/host interface (Fig. 3H). Taken together, these data show that gene expression can be tightly regulated by Dox both in vitro and in vivo.

\subsection{Distal delivery of BDNF increases axonal regeneration into alginate hydrogels}

To analyze overall axonal growth into the scaffold, axons were immunolabeled for $\beta$ III-tubulin. Labeled axons entered the scaffold from both sides and mostly filled the entire length of SC-seeded channels in all groups (Fig. 4A). Axons within the channels extended along SCs in a highly linear pattern parallel to the longitudinal axis of the channel wall irrespective of distal virus injection (Fig. 4B-D). Most axons were located in the center of each channel rather than directly attaching to the capillary wall, similar to our previous findings in alginate hydrogels seeded with BMSCs [11]. Confocal microscopy showed that axons were in close proximity to grafted SCs (Fig. 4E-F).

Quantification of axons within the channels indicated that the number of axons in the middle of the hydrogel was not significantly different from the number at the rostral and caudal end of the alginate channels within each group. Thus, axons grew forward persistently without attenuation in number with increasing distance from the edge.

When BDNF expression in the caudal host parenchyma was turned on, a 1.5-2-fold increase in the number axons per channel area was observed in comparison to subjects without Dox treatment or GFP control animals four weeks after engraftment. In contrast, when BDNF expression was continuously switched off (-Dox), the number of axons was only slightly higher compared to animals that received GFP virus, however this difference was not significant (Fig. 4G, $p>0.05$ at all distances) after 4 weeks. Therefore, caudal BDNF expression augmented axonal growth in the alginate hydrogels and tet-on vectors could be turned off to a level that did not result in significant biological effects in vivo.

Since virally expressed BDNF is relatively high right up to the graft interface, we hypothesized that increased axonal growth even at the most rostral portion of the alginate scaffold might be ascribed to the diffusion of BDNF into the channels. To address this hypothesis, one additional group of Dox-treated animals received the same volume $(8 \mu \mathrm{l})$ of rAAV5-BDNF at a distance of $6 \mathrm{~mm}$ instead of $4 \mathrm{~mm}$ caudal to the hydrogel to move the BDNF gradient more caudally and thereby limit BDNF diffusion into the implant. As the distribution of BDNF measured by ELISA in rAAV5-BDNF-injected animals was similar to that of GFP fluorescence in rAAV5-GFP injected animals (Fig. 3), for this more caudal injection AAV5-BDNF was mixed with 10\% (v/v) of rAAV5-GFP as an indirect indicator of BDNF expression. In contrast to virus injections $4 \mathrm{~mm}$ caudal to the lesion (Fig. 3), GFP fluorescence after more distal injections did not reach the caudal host/graft interface and stopped 200-400 $\mu \mathrm{m}$ caudal to the lesion (Suppl. Fig. 3) 
indicating a lower level of BDNF at the caudal edge of the hydrogel. This more distally located BDNF gradient failed to promote axonal regeneration into the scaffold compared to GFP virus injected animals (Fig. 4G, $p>0.05$ at all distances). Thus, for caudal BDNF virus to increase axonal growth, sufficiently high BDNF levels need to be present right at the caudal host/graft interface.

\subsection{Raphespinal and propriospinal axonal growth into alginate hydrogels}

Raphespinal axons from the brainstem play a vital role in modulating the activity of neural networks in the spinal cord and mediating locomotor function [38]. Immunolabeling for serotonin (5-HT), a neurotransmitter specific for raphespinal axons in the spinal cord, showed that 5-HT-labeled axons regenerated into and extended throughout the channels in all animals (Fig. 5B-F). Viral BDNF expression for 4 weeks in the caudal host parenchyma induced significantly more growth of serotonergic axons into the rostral half of the scaffold in comparison to animals that received rAAV5-BDNF without Dox treatment and GFP control groups regardless of Dox treatment. In the caudal half of the channels, BDNF also triggered more 5-HT ${ }^{+}$axonal penetration compared to GFP control groups (Fig. 5G). However, the number of serotonergic axons in the channels was lower when comparing the rostral and caudal half of the hydrogel, and 5- $\mathrm{HT}^{+}$axons that extended up to the caudal interface of the hydrogel failed to enter the distal host parenchyma. 5- $\mathrm{HT}^{+}$axons were not uniformly distributed, some channels contained bundles of axons whereas other channels did not contain any $5 \mathrm{HT}^{+}$axons. Consistent with our data of overall neurite growth ( $\beta$ III-tubulin) (Fig. 4G), more caudal (6 mm) BDNF virus injections and Dox treatment resulted in a similar number of 5- $\mathrm{HT}^{+}$axons as observed in animals with BDNF virus without Dox treatment (Fig. 5G). An increase in 5-HT axons was also observed when BDNF expression was never turned on in comparison to GFP control animals, but this difference failed to reach significance.

Propriospinal neurons are an important part of spinal neural circuits for relay and connection with other tracts [39]. BDA was used as an anterograde tracer for descending propriospinal and other descending axons of passage in this study. BDA-labeled axons were found to regenerate through the scaffold, and animals that received rAAV5-BDNF injection and Dox treatment had the highest number of axons both in the rostral and caudal halves of the alginate graft (Fig. 6A1-D3). In contrast to serotonergic axons, the number of BDA-labeled axons remained fairly constant from the rostral to the caudal half of the alginate in animals with BDNF expression turned on. Group differences observed within the graft were also found for axons within and beyond the scaffold (Fig. 6F-G). Consistent with 5-HT and $\beta$ III-tubulin labeling, the number of BDA-labeled axons decreased when the BDNF gradient was moved more caudally (6 mm) (Fig. 6E1-E3 and F-G).

Taken together, growth of descending axons is increased within hydrogel scaffolds when BDNF expression is turned on sufficiently close to the alginate hydrogel for 4 weeks, but axons do not extend for significant distances beyond the lesion. 


\subsection{Sustained BDNF expression for axonal regeneration into alginate hydrogels}

To determine whether longer BDNF expression would modify axonal growth responses after implantation of SC-seeded alginate hydrogels, a separate cohort of animals was allowed to survive for 8 weeks post-lesion after injection of BDNF virus (mixed with 10\% GFP virus). Animals underwent continuous ( $8 w k s+$ Dox) or transient ( 4 wks +Dox/4wks -Dox) Dox treatment. Animals that were treated with Dox for 8 weeks showed virus-infected $\mathrm{GFP}^{+}$cells from the caudal injection site right up to the edge of the hydrogel as observed for shorter time points. In animals that received Dox only for the first 4 weeks, GFP fluorescence was absent four weeks after withdrawal of Dox, indicating that viral gene expression can be switched off in vivo (Suppl. Fig. 4).

Overall axonal growth ( $\beta$ III-tubulin labeling) was not altered by the longer time points. Compared to animals killed after 4 weeks of BDNF expression, continuous (8wks +Dox) or transient (4wks +Dox/4wks -Dox) Dox treatment resulted in a similar number of axons within hydrogel channels that remained rather constant at the rostral and caudal end as well as in the middle of the hydrogel (Fig. 7A, D). Similar results were observed for descending axons traced with BDA (Fig. 7C, F). However, the regrowth of 5-HT-labeled serotonergic axons was significantly enhanced at the 8 week time point after rAAV5-BDNF injection. Irrespective of BDNF being persistently ( $8 w k s+$ Dox) or transiently (4wks +Dox/4wks -Dox) expressed, the number of serotonergic axons was significantly increased in comparison with animals that had BDNF expression turned on for only 4 weeks (4wks +Dox) (Fig. 7B, E). Therefore, extending BDNF expression beyond 4 weeks has no overall additive effect, however enhanced growth of some axonal populations given additional time is possible even in the absence of higher BDNF levels.

\subsection{Modification of the graft/host interface by $S C$ injection into the host spinal cord}

In the experiments described above, most of the regenerating descending axons were confined to the caudal interface rather than re-entering into the host parenchyma even in the presence of a distal BDNF gradient and extended periods for long distance growth (Fig. 6G and Fig. 8A). The fibroglial scar surrounding the graft is one potential obstacle impeding axonal regeneration into the distal spinal cord $[2,40]$. To modify the permissiveness of the scar at the caudal hydrogel/graft interface and to further facilitate axonal growth, we additionally injected GFP-transgenic SCs into the host tissue $1 \mathrm{~mm}$ caudal to the alginate hydrogel in one group of animals that received caudal rAAV5-BDNF injection. Animals were treated with Dox and survived for 8 weeks. SCs seeded within the hydrogel were not GFP-labeled. Injected GFP ${ }^{+}$ transgenic SCs migrated from the injection site, and some entered the capillaries of the hydrogel (Fig. 8F) even approaching the rostral graft/host interface. Interestingly, the combination of SC injection and BDNF expression for 8 weeks in the caudal spinal cord not only significantly increased the overall number of $\beta$ III-tubulin-labeled axons regenerating into the hydrogel (Fig. 7D), but also doubled the number of 5-HT- (Fig. 7E) and BDA-labeled axons (Fig. 7F) growing into the channels compared to animals that underwent the same treatment without additional SC injection. 
Most importantly, more BDA-labeled descending axons penetrated the caudal alginate/host interface and entered the host parenchyma when the caudal spinal cord was injected with SCs and BDNF expression was turned on for 8 weeks (Fig. 8E). A significantly increased number of BDA-labeled axons were found up to $1200 \mu \mathrm{m}$ beyond the caudal hydrogel interface and extended along the migration pathway of injected SCs, which were intermingled with host astrocytes. A small portion of axons was also detected in the caudal host parenchyma at a long distance $(>2000 \mu \mathrm{m})$ further caudal than the SC injection site (Fig. 8B and D-F).

\section{Discussion}

The present study systematically investigated the parameters needed to achieve axonal regeneration across an anisotropic capillary alginate hydrogel in a lateral hemisection lesion. Our data indicate that 1) transient expression of BDNF is sufficient to sustain regenerated axons, 2) some axonal populations continue to show increased growth beyond 4 weeks post-lesion even when BDNF expression has been turned off and 3) additional grafting of SCs beyond the lesion site is essential for axons to bridge across the lesion and to re-enter the caudal host tissue. In previous decades, biomaterials with different structural properties have been investigated in combination with a variety of strategies to facilitate axonal growth across a lesion after SCI [41, 42]. One major advantage of biomaterials with linearized channels is the ability to guide axonal growth in a defined linear pattern allowing for more axons to regenerate across the lesion towards the distal host tissue for further sprouting and potential new connections [40]. In addition, channels provide space for the delivery of cells and bio-active molecules to improve therapeutic efficacy. Increased axonal regrowth was detected after implantation of poly(D,L-lactide-co-glycolide) (PLGA) scaffolds seeded with human mesenchymal stem cells into the channels [43]. Similar results were observed by engraftment of agarose scaffolds with encapsulated BDNF [44] or pre-seeded with BMSCs overexpressing NT-3 [40] in uniaxial channels. However, axonal regeneration terminated at the graft/host interface in most studies rather than extending into the host spinal cord to make new synaptic connections. The reactive cell matrix forming around a graft is a prominent obstacle impeding axonal growth into the host parenchyma [40].

To overcome this impediment, we first aimed to generate a BDNF gradient caudal to the graft to induce axonal growth beyond the alginate hydrogel. In previous studies using a cell suspension graft at the lesion site and lentiviral NT-3 gene transfer rostral to the lesion, we have shown that gradients of neurotrophins can enhance short distance bridging of ascending sensory axons [45]. Distal delivery of BDNF has also been shown to promote some short distance growth of reticulospinal axon populations when lesions extended no more than $0.5-1 \mathrm{~mm}$ [31]. The current results also demonstrate that viral BDNF expression caudal to the lesion enhances axonal growth and augments the pro-regenerative effect of alginate channels pre-seeded with SCs. In addition, more than $50 \%$ of raphespinal and $80 \%$ of BDA-labeled descending axons found in the rostral half of the alginate biomaterial continue to extend over the caudal half of the $2 \mathrm{~mm}$ alginate hydrogel. Diffusion of BDNF from the caudal host tissue into the channels likely contributed to the increased growth as animals injected with rAAV-GFP never showed any transfected cells 
within the graft. Yet, similar to studies using agarose or alginate scaffolds with channels in combination with cellular BDNF delivery within the biomaterial $[11,46]$, most of the descending axons failed to extend beyond the alginate hydrogels even when BDNF expression was extended up to 2 months post-injury (Fig. 6-7). It is possible that the widespread increase in BDNF established by rAAV5 caudal to the lesion does not provide a sufficiently steep growth factor gradient to attract axons beyond the caudal scar tissue. Delivery of neurotrophic factors using less diffusible vectors, e.g. rAAV2 or lentiviral vectors may help to create a more effective, localized gradient and propel axonal penetration into the host tissue.

The second strategy in this study to enhance bridging axonal regeneration was the injection of syngeneic SCs in the caudal spinal cord in combination with BDNF delivery. Caudally injected SCs generated a cellular trail from alginate channels into the host tissue enabling BDA-traced descending axons to extend into the adjacent caudal spinal cord identified by GFAP labeling. Distal Schwann cell injections appeared to disrupt the distinct astroglial border usually found directly adjacent to the hydrogel. Axons extending along these Schwann cells were therefore able to reach more distal areas of the host spinal cord, where astrogliosis is less prevalent and more favorable for axonal bridging. Surprisingly, caudal SC injection also increased descending axon growth into the alginate. Given that SCs migrated towards the hydrogel, entered the channels, and often even approached the rostral host/graft interface, it is possible that the injected SCs served as an exogenous "cell bank" and supplemented dying SCs pre-seeded within the scaffold. From other studies, it is known that a large proportion of SCs grafted to the injured spinal cord gradually die via apoptosis [47]. Alternatively, the injected SCs might have been transfected by rAAV5-BDNF injected further caudally and thereby magnified the regenerative response of axons when they migrated into the channels. Compared to our previous studies using alginate hydrogels that were filled with bone marrow stromal cells and grafted in the same lesion model, seeding channels with SCs not only promoted growth of a greater number of axons, but axonal extension was also sustained continuously throughout the channels and a decrease in axon number in the center of the hydrogels was not observed [11]. Due to the nature of the lesion (lateral hemisection), we cannot definitively exclude the possibility that some BDA-labeled axons found caudal to the lesion site were derived from collateral sprouting from the contralateral side. However, some axons could be clearly traced from alginate channels into the caudal spinal cord and the decline in axon numbers with increasing distance from the alginate also suggests that these axons had extended through the hydrogel. Studies in complete transections will be better suited to answer this question by histological and electrophysiological means.

In contrast to most previous studies using viral neurotrophin delivery, the current study used a tetracycline-inducible vector for BDNF expression. The temporal regulation of BDNF expression to enhance axonal growth is essential for clinical translation, given the adverse effects observed with long-term BDNF delivery $[30,31]$. The controlled expression allowed us to determine whether high levels of BDNF for 2 months results in superior axonal growth compared to short-term one month delivery. Neither overall axonal growth, nor growth of serotonergic nor other BDA-labeled descending tracts differed between short and long-term 
delivery. However, we observed more axon growth at 2 months compared to 1 month independent of high BDNF levels indicating that either SC-derived factors or very small BDNF levels from leaky vector-derived gene expression are sufficient to further improve regenerative growth. These longer-term studies also confirmed the excellent bio-compatibility of alginate-based hydrogels as previously reported at shorter time points [11]. As a crucial structure for axonal guidance, the linearized microstructure within the scaffold was stable for at least 8 weeks after in vivo implantation. No obvious cavities were detected around the scaffold, which is beneficial for axonal growth and cellular survival (Figs. 2 and 4).

In the current experiment, animals were not tested for behavioral recovery. Lateral hemisection lesions extending over $2 \mathrm{~mm}$ at C5 destroy many neurons at segmental level (motor neurons, interneurons) required for upper forelimb movement and even very small differences in the mediolateral lesion extent possibly sparing some corticospinal axons profoundly influence functional outcomes. Small gains in motor performance due to regenerated axons might therefore not be detectable. While the current combinatorial strategy allows for the re-entry of axons into the host tissue, a premise for synapse formation and functional restoration [48], examining regeneration and functional recovery in complete transections would be better suited to prove that regenerated axons causally underlie any behavioral effects.

\section{Conclusion}

Alginate hydrogels with anisotropic capillaries support the survival of grafted SCs and guide supraspinal and propriospinal descending axons through and beyond the lesion site. The number of axons bridging the lesion significantly increases when caudal BDNF expression is activated. A combination of SC injection and BDNF overexpression in the caudal spinal cord further promotes axonal growth and penetration into the host parenchyma. Future studies will investigate the efficacy of the alginate hydrogel-based transplantation after SCI to improve functional outcomes.

\section{Acknowledgements}

Supported by grants from the Deutsche Forschungsgemeinschaft (BL414/3-1) (to A.B. and N.W.), International Foundation for Research in Paraplegia, International Spinal Research Trust, the Indiana University Health - Indiana University School of Medicine Strategic Research Initiative, Indiana Spinal Cord and Brain Injury Research Fund and Morton Cure Paralysis Fund to A.B. and a Heinz Götze Memorial Fellowship to S.L.. A.C. and L.T were supported by a EU FP7 Marie Curie IAPP grant (contract 286071). We would like to thank the Missouri Rat Resource Center for providing GFP-transgenic rats.

\section{Conflicts of interest:}

None

\section{Contributors:}


S.L., A.B. and N.W. wrote the article, L.N., A.C. and L.T. cloned the vector, R.M. generated the biomaterials, S.L., R.P., N.W. and A.B. designed and interpreted the experiments, S.L., B.S. and T.S. did the animal surgeries, tissue labeling, quantification and analysis. 


\section{FIGURE LEGENDS}

Fig. 1. Lesion paradigm and experimental procedures. (A) Schematic diagram of the experimental design. A 1.5-2 mm long segment of the spinal cord was removed unilaterally at the C5 level before implanting a Schwann cell (SC)-seeded alginate scaffold. Subsequently, viral vectors (yellow) for the regulatable expression of GFP (rAAV5-GFP) or BDNF (rAAV5-BDNF) were injected into the caudal spinal cord ipsilateral to the lesion. SCs (blue) were also injected into the caudal spinal cord in one group. Biotinylated dextran amine (BDA, red) was injected in the spinal cord rostral to the lesion to trace descending axons three or seven weeks post-lesion. (A1) Cross-sectional and (A2) longitudinal view of the capillary lumen. (B) After a hemisection lesion (arrowhead, $\sim 2 \mathrm{~mm}$ in length) of the rat spinal cord, (C) the alginate scaffold loaded with SCs (white arrow) was grafted into the lesion and (D) virus $(*)$ or SCs (black arrow) were injected into the spinal cord caudal to the scaffold using a glass capillary. Scale bar: $300 \mu \mathrm{m}$ in (A1); $500 \mu \mathrm{m}$ in (A2).

Fig. 2. Integration of alginate hydrogels and Schwann cell (SC) survival. (A) Dorsal and (B) ventral view of the scaffold (arrows) in the spinal cord 4 weeks after engraftment. (C) Nuclear staining (DAPI) indicates that scaffold channels are filled with cells, and cavities at the host/graft interface are very limited in number and size. (D) Four weeks after engraftment, GFP-labeled SCs (green) survive within and around the alginate scaffold, connecting the scaffold to the host tissue identified by GFAP labeling (gray). Higher magnifications of the graft/host interface (dashed lines) are shown in $(\mathbf{E}, \mathbf{F})$. In $(\mathbf{E})$, stars (*) label cell-seeded channels and triangles $(\Delta)$ indicate the walls of the scaffold. Scale bar: $500 \mu \mathrm{m}$ in $(\mathbf{C}, \mathbf{D}) ; 100 \mu \mathrm{m}$ in $(\mathbf{E}, \mathbf{F})$.

Fig. 3. Characterization of tet-regulated GFP and BDNF expression in vivo. (A, B) GFP fluorescence (green) in the spinal cord of animals injected with rAAV5-GFP. (A) Only a few GFP expressing cells are found around the injection site in animals without doxycycline (Dox) treatment. (B) In contrast, strong GFP fluorescence is observed in Dox-treated animals spreading from the GFP virus injection site to the caudal graft/host interface (dashed line). (C-E) Higher magnification of the areas boxed in (A, B). Arrows in (A, B) indicate virus injection site. (F) Overall BDNF levels in the ipsilateral caudal spinal cord quantified by ELISA indicates significant higher BDNF levels in Dox-treated animals that received rAAV5-BDNF injection (***p<0.001, one-way ANOVA followed by Tukey's post hoc analysis). (G) Differences in BDNF leyels within the alginate scaffolds did not reach significance (n.s, not significant). (H) rAAV5-BDNF injection in the spinal cord established a BDNF gradient with highest levels around the injection site $\left({ }^{* * *} p<0.001\right.$; two-way ANOVA followed by Bonferroni post hoc test). Scale bar: $500 \mu \mathrm{m}$ in $(\mathbf{A}, \mathbf{B}) ; 100 \mu \mathrm{m}$ in $(\mathbf{C}-\mathbf{E})$. Inset in $(\mathbf{H})$ indicates the tissue (yellow) used for BDNF ELISA.

Fig. 4. Axonal growth into SC-seeded alginate scaffolds 4 weeks post-implantation. (A) $\beta$ III-tubulin (red) immunolabeling of the lesion site in an animal that was implanted with an alginate hydrogel seeded with GFP-transgenic SCs and received caudal BDNF virus injection 
and Dox treatment. (B-E) Higher magnification of areas boxed in (A) show similar numbers of $\beta$ III-tubulin-labeled axons (red) at (B) the rostral, (C) center and (D) caudal area of the alginate hydrogel extending along GFP-positive SCs (green) in the capillaries of the scaffolds. Dashed lines in (B) and (D) indicate edges of the hydrogel. (E) Confocal imaging (z-stack) and (F) cross plane of the area indicated by the dashed line in $(\mathbf{E})$ indicates axons in the capillaries are in close contact or ensheathed by grafted GFP-positive SCs (arrowheads). (G) Quantification of axons within the scaffolds indicates significant higher number of axons at all distances in animals that received BDNF virus $4 \mathrm{~mm}$ caudal to the scaffold when gene expression was turned on $\left(* * * p<0.001\right.$ vs GFP -Dox; \#\#\#p<0.001 vs GFP +Dox; ${ }^{\&} p<0.05,{ }^{\& \&} p<0.01$ vs BDNF -Dox; ${ }^{\wedge} p<0.05,{ }^{\wedge} p<0.01,{ }^{\wedge \wedge} p<0.001 v s \mathrm{BDNF} /+\operatorname{Dox}(6 \mathrm{~mm})$; two-way ANOVA followed by Bonferroni post hoc test). Scale bar: $500 \mu \mathrm{m}$ in (A); $100 \mu \mathrm{m}$ in (B-D); $20 \mu \mathrm{m}$ in (E); $4 \mu \mathrm{m}$ in (F).

Fig. 5. Regeneration of serotonergic axons into alginate scaffolds. (A) Schematic representation of the scaffold in the spinal cord and location (box) where images in (B-F) were taken. (B-F) Serotonergic (5-HT-labeled) axons enter the scaffolds and extend along the channels. (G) Quantification of 5-HT-labeled axons within the scaffolds indicates higher number of 5-HT-positive axons in animals with BDNF expression turned on $(* p<0.05 ; * * p<0.01$; $* * * p<0.001$; one-way ANOVA followed by Tukey's post hoc analysis). Scale bar: $100 \mu \mathrm{m}$ in (B-F).

Fig. 6. Penetration of descending BDA-labeled axons through alginate scaffolds. (A1-E3) Propriospinal and other descending axons traced with BDA grow through the scaffolds in rostro-caudal direction. Schematics on top depict regions where images were taken. Dashed lines in (A1, B1, C1, D1, E1) and (A3, B3, C3, D3, E3) indicate the rostral and caudal edges of the scaffold, respectively. Axons extending through the scaffold terminate just caudal to the scaffold. (F) Quantification of BDA-labeled descending axons regenerated into the rostral and caudal half of scaffolds shows significant higher numbers in animals with BDNF virus when gene expression is turned on. (G) Similar differences are observed for BDA-labeled axonal profiles just beyond the caudal edge of scaffolds $\left({ }^{*} p<0.05 ; * * p<0.01 ; * * * p<0.001\right.$; one-way ANOVA followed by Tukey's post hoc analysis). Scale bar: $100 \mu \mathrm{m}$ in (A1-E3).

Fig. 7. Long-term BDNF expression combined with SC injection for axonal growth within the alginate hydrogel. Representative images for (A) overall axon growth, (B) serotonergic axons and (C) BDA-labeled descending axons within the scaffold 8 weeks post-lesion with continuous caudal BDNF expression. Schematics on top of $(\mathbf{B}, \mathbf{C})$ depict regions where images were taken. (D-F) Quantification of (D) overall axonal growth, (E) serotonergic axons and (F) descending propriospinal axons within the channels. Significantly more axons are found in animals that received rAAV5-BDNF when gene expression is turned on and SCs are injected caudal to the lesion $\left({ }^{*} p<0.05,{ }^{*} * p<0.01\right.$ vs rAAV5-BDNF/4wks +Dox; ${ }^{*} p<0.05,{ }^{\# \#} p<0.01$ vs rAAV5-BDNF/4wks +Dox/4wks -Dox; ${ }^{\&} p<0.05,{ }^{\&} \& p<0.01$ vs rAAV5-BDNF/8wks +Dox; two-way ANOVA followed by Bonferroni post test). The same group also shows the highest 
level of serotonergic and BDA-labeled axons $\left(* p<0.05 ; * * p<0.01\right.$; ${ }^{* * *} p<0.001$; one-way ANOVA followed by Tukey's post hoc analysis). Dashed line in (C) indicates caudal edge of the hydrogel. Scale bar: $500 \mu \mathrm{m}$ in $(\mathbf{A}) ; 100 \mu \mathrm{m}$ in $(\mathbf{B}, \mathbf{C})$.

Fig. 8. Caudal injection of SCs allows for descending BDA-labeled axons to extend beyond the alginate scaffolds. (A, C) Most BDA-labeled axons (red) fail to extend beyond the graft/host interface (dashed line) demarcated by GFAP-labeled astrocytes (cyan) in animals that received SC-seeded alginate scaffolds and caudal BDNF virus injection despite survival for 8 weeks in the presence of doxycycline (gene expression turned on). (B, D) In contrast, descending BDA-labeled axons regenerate through the entire hydrogel and the caudal interface (dashed line) into the host tissue identified by GFAP labeling into and beyond areas occupied by (F) injected $\mathrm{GFP}^{+} \mathrm{SCs}$ in animals with caudal BDNF virus injection and additional SC injection. Axons (arrowheads) elongate into the distal host spinal cord beyond the SC grafts. (E) Quantification of axons regenerated beyond the caudal edge of the scaffold $(* \mathrm{p}<0.05 ; * * \mathrm{p}<0.01 ; * * * \mathrm{p}<0.001$; one-way ANOVA followed by Tukey's post hoc analysis). SC injection site is indicated by arrow. Scale bar: $300 \mu \mathrm{m}$ in $(\mathbf{A}-\mathbf{D}, \mathbf{F})$.

Suppl. Fig. 1. Vector map and in vitro regulation of gene expression. (A) Plasmid map of the tet-regulated AAV vector. Expression of the reverse tetracycline (tet) transactivator (rtTA) and enhanced GFP (eGFP) or human BDNF (huBDNF) is driven by a bi-directional tet-regulated promoter ( ptet $\left._{\text {bidi }}\right)$. ITR, inverted terminal repeat; SV40pA, SV40 polyadenylation signals. (B-E) GFP fluorescence was detected in 293T cells 24h after transfection with the rAAV-rtTAV16-GFP plasmid, but not rAAV-rtTAV16-BDNF plasmid. (F) Quantitative analysis shows a significant increase of $\mathrm{GFP}^{+}$cell number when the wells are treated with $1 \mu \mathrm{g} / \mathrm{ml}$ Dox. (G) BDNF levels are significantly higher in the supernatant of cells transfected with rAAV-rtTAV16-BDNF and treated with Dox (+Dox) $\left({ }^{*} p<0.05 ; * * * p<0.001\right.$; Kruskal-Wallis followed by Dunn's test). Scale bar: $100 \mu \mathrm{m}$ in (B-E).

Suppl. Fig. 2. Characterization of rAAV5-GFP infected cells. Double immunofluorescence labeling for GFP and glial and neuronal markers shows co-localization of GFP with (A, B) astrocytes (GFAP) and (C, D) oligodendrocytes (olig2). Confocal images confirm co-localization of (E) NeuN and (F) GFAP with GFP. Arrows indicate examples of double-labeled cells. Scale bars: $100 \mu \mathrm{m}$ in (A-D), $50 \mu \mathrm{m}$ in $(\mathbf{E}, \mathbf{F})$.

Suppl. Fig. 3. Diffusion pattern of tet vectors after a more caudal (6 mm) injection. (A) GFP fluorescence in the spinal cord after injection of rAAV5-BDNF containing $10 \%(\mathrm{v} / \mathrm{v})$ of rAAV5-GFP $6 \mathrm{~mm}$ caudal to the lesion. GFP-labeled cells can be detected in the caudal spinal cord, but do not reach the graft/host interface (dashed line). (B, C) Higher magnification of the areas boxed in (A). Scale bar: $500 \mu \mathrm{m}$ in $(\mathbf{A}) ; 100 \mu \mathrm{m}$ in $(\mathbf{B}, \mathbf{C})$. 
Suppl. Fig. 4. Long-term regulation of tet vectors in vivo. (A, B) GFP fluorescence in the spinal cord after injection of rAAV5-BDNF containing 10\% (v/v) rAAV5-GFP $4 \mathrm{~mm}$ caudal to the lesion. (A) No $\mathrm{GFP}^{+}$cells are visible in the caudal spinal cord of animals treated with doxycycline (Dox) for 4 weeks followed by withdrawal of Dox for 4 weeks. (B) GFP fluorescence can be easily detected in the caudal spinal cord of animals continuously treated with Dox for 8 weeks. (C-E) Higher magnification of the areas boxed in (A, B). Scale bar: $500 \mu \mathrm{m}$ in $(\mathbf{A}, \mathbf{B}) ; 100 \mu \mathrm{m}$ in $(\mathbf{C}-\mathbf{E})$. 
Liu et al.

\section{References}

[1] A. Blesch, M.H. Tuszynski, Spinal cord injury: plasticity, regeneration and the challenge of translational drug development, Trends Neurosci 32(1) (2009) 41-7.

[2] J.M. Cregg, M.A. DePaul, A.R. Filous, B.T. Lang, A. Tran, J. Silver, Functional regeneration beyond the glial scar, Exp Neurol 253 (2014) 197-207.

[3] M. Kim, S.R. Park, B.H. Choi, Biomaterial scaffolds used for the regeneration of spinal cord injury (SCl), Histol Histopathol 29(11) (2014) 1395-1408.

[4] H. Kanno, Y. Pressman, A. Moody, R. Berg, E.M. Muir, J.H. Rogers, H. Ozawa, E. Itoi, D.D. Pearse, M.B. Bunge, Combination of engineered Schwann cell grafts to secrete neurotrophin and chondroitinase promotes axonal regeneration and locomotion after spinal cord injury, J Neurosci 34(5) (2014) 1838-1855.

[5] A. Blesch, P. Lu, S. Tsukada, L.T. Alto, K. Roet, G. Coppola, D. Geschwind, M.H. Tuszynski, Conditioning lesions before or after spinal cord injury recruit broad genetic mechanisms that sustain axonal regeneration: superiority to camp-mediated effects, Exp Neurol 235(1) (2012) 162-73.

[6] J. Ruschel, F. Hellal, K.C. Flynn, S. Dupraz, D.A. Elliott, A. Tedeschi, M. Bates, C. Sliwinski, G. Brook, K. Dobrindt, M. Peitz, O. Brustle, M.D. Norenberg, A. Blesch, N. Weidner, M.B. Bunge, J.L. Bixby, F. Bradke, Axonal regeneration. Systemic administration of epothilone B promotes axon regeneration after spinal cord injury, Science 348(6232) (2015) 347-52.

[7] H.M. Geller, J.W. Fawcett, Building a bridge: engineering spinal cord repair, Exp Neurol 174(2) (2002) 125-36.

[8] P. Prang, R. Muller, A. Eljaouhari, K. Heckmann, W. Kunz, T. Weber, C. Faber, M. Vroemen, U. Bogdahn, N. Weidner, The promotion of oriented axonal regrowth in the injured spinal cord by alginate-based anisotropic capillary hydrogels, Biomaterials 27(19) (2006) 3560-9.

[9] K. Pawar, P. Prang, R. Willer, M. Caioni, U. Bogdahn, W. Kunz, N. Weidner, Intrinsic and extrinsic determinants of central nervous system axon outgrowth into alginate-based anisotropic hydrogels, Acta Biomater 27 (2015) 131-139.

[10] K. Pawar, R. Mueller, M. Caioni, P. Prang, U. Bogdahn, W. Kunz, N. Weidner, Increasing capillary diameter and the incorporation of gelatin enhance axon outgrowth in alginate-based anisotropic hydrogels, Acta Biomater $7(7)$ (2011) 2826-2834.

[11] M.I. Gunther, N. Weidner, R. Muller, A. Blesch, Cell-seeded alginate hydrogel scaffolds promote directed linear axonal regeneration in the injured rat spinal cord, Acta Biomater 27 (2015) 140-150.

[12] M.I. Gunther, M. Gunther, M. Schneiders, R. Rupp, A. Blesch, AngleJ: A new tool for the automated measurement of neurite growth orientation in tissue sections, J Neurosci Methods 251 (2015) 143-50.

[13] M.B. Bunge, Efficacy of Schwann cell transplantation for spinal cord repair is improved with combinatorial strategies, J Physiol 594(13) (2016) 3533-8.

[14] D.D. Pearse, A.R. Sanchez, F.C. Pereira, C.M. Andrade, R. Puzis, Y. Pressman, K. Golden, B.M. Kitay, B. Blits, P.M. Wood, M.B. Bunge, Transplantation of Schwann cells and/or olfactory ensheathing glia into the contused spinal cord: Survival, migration, axon association, and functional recovery, Glia 55(9) (2007) 976-1000.

[15] D.D. Pearse, F.C. Pereira, A.E. Marcillo, M.L. Bates, Y.A. Berrocal, M.T. Filbin, M.B. Bunge, cAMP and Schwann cells promote axonal growth and functional recovery after spinal cord injury, Nat Med 10(6) (2004) 610-616.

[16] N. Weidner, A. Blesch, R.J. Grill, M.H. Tuszynski, Nerve growth factor-hypersecreting Schwann cell grafts augment and guide spinal cord axonal growth and remyelinate central nervous system axons in a phenotypically appropriate manner that correlates with expression of L1, J Comp Neurol 413(4) (1999) 495-506. 
[17] K.L. Golden, D.D. Pearse, B. Blits, M.S. Garg, M. Oudega, P.M. Wood, M.B. Bunge, Transduced Schwann cells promote axon growth and myelination after spinal cord injury, Exp Neurol 207(2) (2007) 203-217.

[18] S.X. Zhang, F. Huang, M. Gates, E.G. Holmberg, Role of endogenous Schwann cells in tissue repair after spinal cord injury, Neural Regen Res 8(2) (2013) 177-85.

[19] K. Bhatheja, J. Field, Schwann cells: Origins and role in axonal maintenance and regeneration, Int J Biochem Cell Biol 38(12) (2006) 1995-1999.

[20] R.R. Wiliams, M.B. Bunge, Schwann cell transplantation: A repair strategy for spinal cord injury?, Prog Brain Res 201 (2012) 295-312.

[21] V. Patel, G. Joseph, A. Patel, S. Patel, D. Bustin, D. Mawson, L.M. Tuesta, R. Puentes, M. Ghosh, D.D. Pearse, Suspension matrices for improved Schwann-cell survival after implantation into the injured rat spinal cord, J Neurotrauma 27(5) (2010) 789-801.

[22] R.R. Williams, M. Henao, D.D. Pearse, M.B. Bunge, Permissive Schwann cell graft/spinal cord interfaces for axon regeneration, Cell Transplant 24(1) (2015) 115-131.

[23] G.J. Ritfeld, A. Patel, A. Chou, T.L. Novosat, D.G. Castillo, R.A.C. Roos, M. Oudega, The role of brain-derived neurotrophic factor in bone marrow stromal cell-mediated spinal cord repair, Cell Transplant 24(11) (2015) 2209-2220.

[24] M. Sasaki, C. Radtke, A.M. Tan, P. Zhao, H. Hamada, K. Houkin, O. Honmou, J.D. Kocsis, BDNF-hypersecreting human mesenchymal stem cells promote functional recovery, axonal sprouting, and protection of corticospinal neurons after spinal cord injury, J Neurosci 29(47) (2009) 14932-14941.

[25] M. Hayashi, T. Ueyama, K. Nemoto, T. Tamaki, E. Senba, Sequential mRNA expression for immediate early genes, cytokines, and neurotrophins in spinal cord injury, J Neurotrauma 17(3) (2000) 203-218.

[26] J.H. Brock, E.S. Rosenzweig, A. Blesch, R. Moseanko, L.A. Havton, V.R. Edgerton, M.H. Tuszynski, Local and remote growth factor effects after primate spinal cord injury, J Neurosci 30(29) (2010) 9728-9737.

[27] N.I. Bamber, H.Y. Li, X.B. Lu, M. Oudega, P. Aebischer, X.M. Xu, Neurotrophins BDNF and NT-3 promote axonal re-entry into the distal host spinal cord through Schwann cell-seeded mini-channels, Eur J Neurosci 13(2) (2001) 257-268.

[28] P. Lu, L.L. Jones, M.H. Tuszynski, BDNF-expressing marrow stromal cells support extensive axonal growth at sites of spinal cord injury, Exp Neurol 191(2) (2005) 344-360.

[29] A. Blesch, M.H. Tuszynski, Transient growth factor delivery sustains regenerated axons after spinal cord injury, J Neurosci 27(39) (2007) 10535-10545.

[30] K. Fouad, D.J. Bennett, R. Vavrek, A. Blesch, Long-term viral brain-derived neurotrophic factor delivery promotes spasticity in rats with a cervical spinal cord hemisection, Front Neurol 4 (2013) 187.

[31] P. Lu, A. Blesch, L. Graham, Y.Z. Wang, R. Samara, K. Banos, V. Haringer, L. Havton, N. Weishaupt, D. Bennett, K. Fouad, M.H. Tuszynski, Motor axonal regeneration after partial and complete spinal cord transection, J Neurosci 32(24) (2012) 8208-8218.

[32] M. Gossen, H. Bujard, Tight control of gene expression in mammalian cells by tetracycline-responsive promoters, Proc Natl Acad Sci U S A 89(12) (1992) 5547-51.

[33] A.T. Das, L. Tenenbaum, B. Berkhout, Tet-On systems for doxycycline-inducible gene expression, Curr Gene Ther 16(3) (2016) 156-67.

[34] A. Chtarto, H.U. Bender, C.O. Hanemann, T. Kemp, E. Lehtonen, M. Levivier, J. Brotchi, T. Velu, L. Tenenbaum, Tetracycline-inducible transgene expression mediated by a single AAV vector, Gene Ther 10(1) (2003) 84-94. 
[35] M. Gossen, S. Freundlieb, G. Bender, G. Muller, W. Hillen, H. Bujard, Transcriptional activation by tetracyclines in mammalian cells, Science 268(5218) (1995) 1766-9.

[36] X. Zhou, M. Vink, B. Klaver, B. Berkhout, A.T. Das, Optimization of the Tet-On system for regulated gene expression through viral evolution, Gene Ther 13(19) (2006) 1382-90.

[37] C. Burger, O.S. Gorbatyuk, M.J. Velardo, C.S. Peden, P. Williams, S. Zolotukhin, P.J. Reier, R.J. Mandel, N. Muzyczka, Recombinant AAV viral vectors pseudotyped with viral capsids from serotypes 1,2 , and 5 display differential efficiency and cell tropism after delivery to different regions of the central nervous system, Mol Ther: 10(2) (2004) 302-17.

[38] M. Ghosh, D.D. Pearse, The role of the serotonergic system in locomotor recovery after spinal cord injury, Front Neural Circuits 8 (2014) 151.

[39] L. Filli, A.K. Engmann, B. Zorner, O. Weinmann, T. Moraitis, M. Gullo, H. Kasper, R. Schneider, M.E. Schwab, Bridging the gap: a reticulo-propriospinal detour bypassing an incomplete spinal cord injury, J Neurosci 34(40) (2014) 13399-410.

[40] T. Gros, J.S. Sakamoto, A. Blesch, L.A. Havton, M.H. Tuszynski, Regeneration of long-tract axons through sites of spinal cord injury using templated agarose scaffolds, Biomaterials 31(26) (2010) 6719-6729.

[41] O.A. Carballo-Molina, I. Velasco, Hydrogels as scaffolds and delivery systems to enhance axonal regeneration after injuries, Front Cell Neurosci 9 (2015) 13.

[42] I. Elliott Donaghue, R. Tam, M.V. Sefton, M.S. Shoichet, Cell and biomolecule delivery for tissue repair and regeneration in the central nervous system, J Control Release : 190 (2014) 219-27.

[43] R. Cholas, H.P. Hsu, M. Spector, Collagen scaffolds incorporating select therapeutic agents to facilitate a reparative response in a standardized hemiresection defect in the rat spinal cord, Tissue engineering. Part $A$ 18(19-20) (2012) 2158-72.

[44] S. Stokols, M.H. Tuszynski, Freeze-dried agarose scaffolds with uniaxial channels stimulate and guide linear axonal growth following spinal cord injury, Biomaterials 27(3) (2006) 443-51.

[45] L. Taylor, L. Jones, M.H. Tuszynski, A. Blesch, Neurotrophin-3 gradients established by lentiviral gene delivery promote short-distance axonal bridging beyond cellular grafts in the injured spinal cord, J Neurosci 26(38) (2006) 9713-9721.

[46] M.Y. Gao, P. Lu, B. Bednark, D. Lynam, J.M. Conner, J. Sakamoto, M.H. Tuszynski, Templated agarose scaffolds for the support of motor axon regeneration into sites of complete spinal cord transection, Biomaterials 34(5) (2013) 1529-1536.

[47] C.E. Hill, A. Hurtado, B. Blits, B.A. Bahr, P.M. Wood, M.B. Bunge, M. Oudega, Early necrosis and apoptosis of Schwann cells transplanted into the injured rat spinal cord, Eur J Neurosci 26(6) (2007) 1433-1445.

[48] M.H. Tuszynski, O. Steward, Concepts and methods for the study of axonal regeneration in the CNS, Neuron 74(5) (2012) 777-91. 
Liu et al.
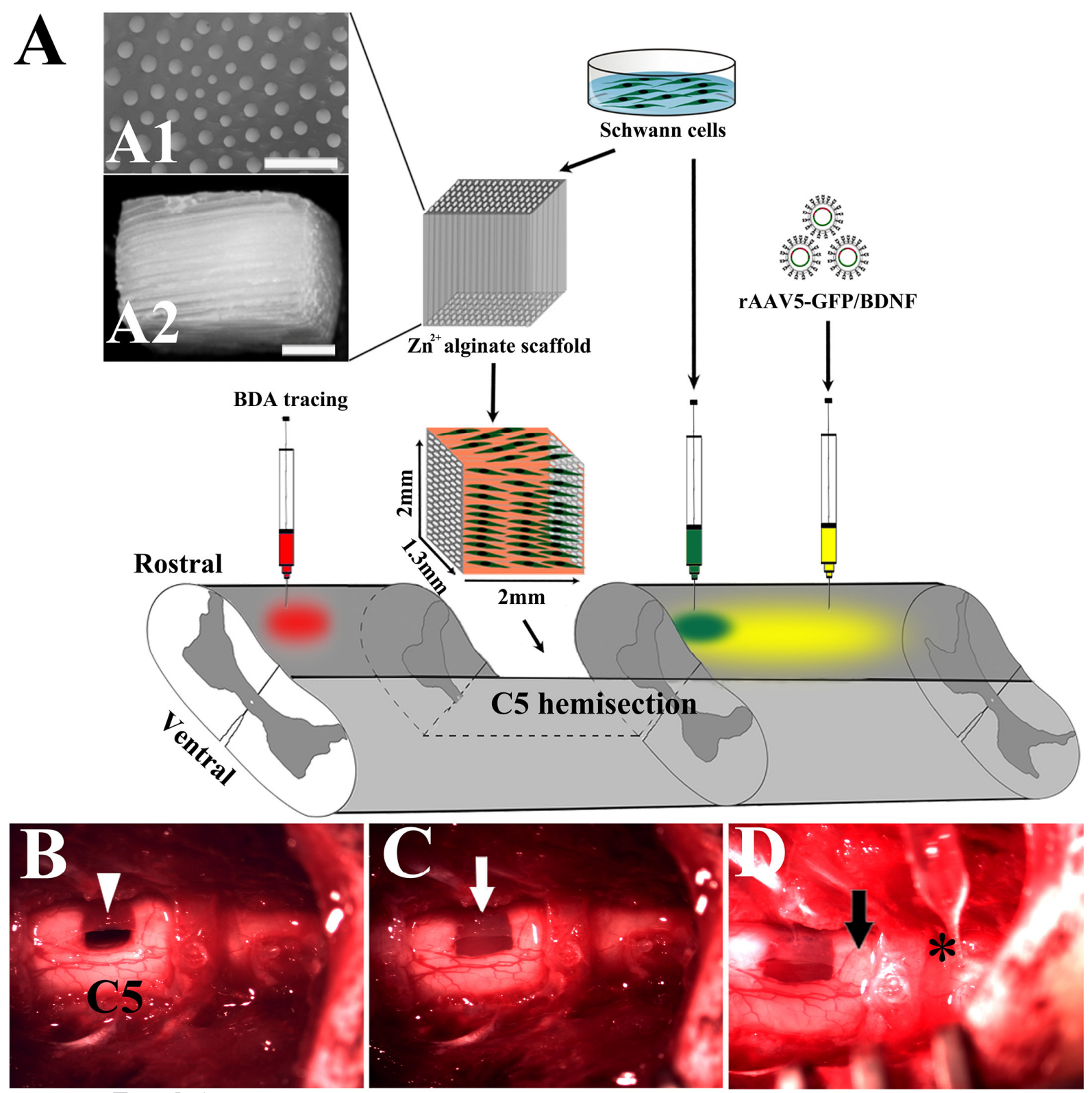

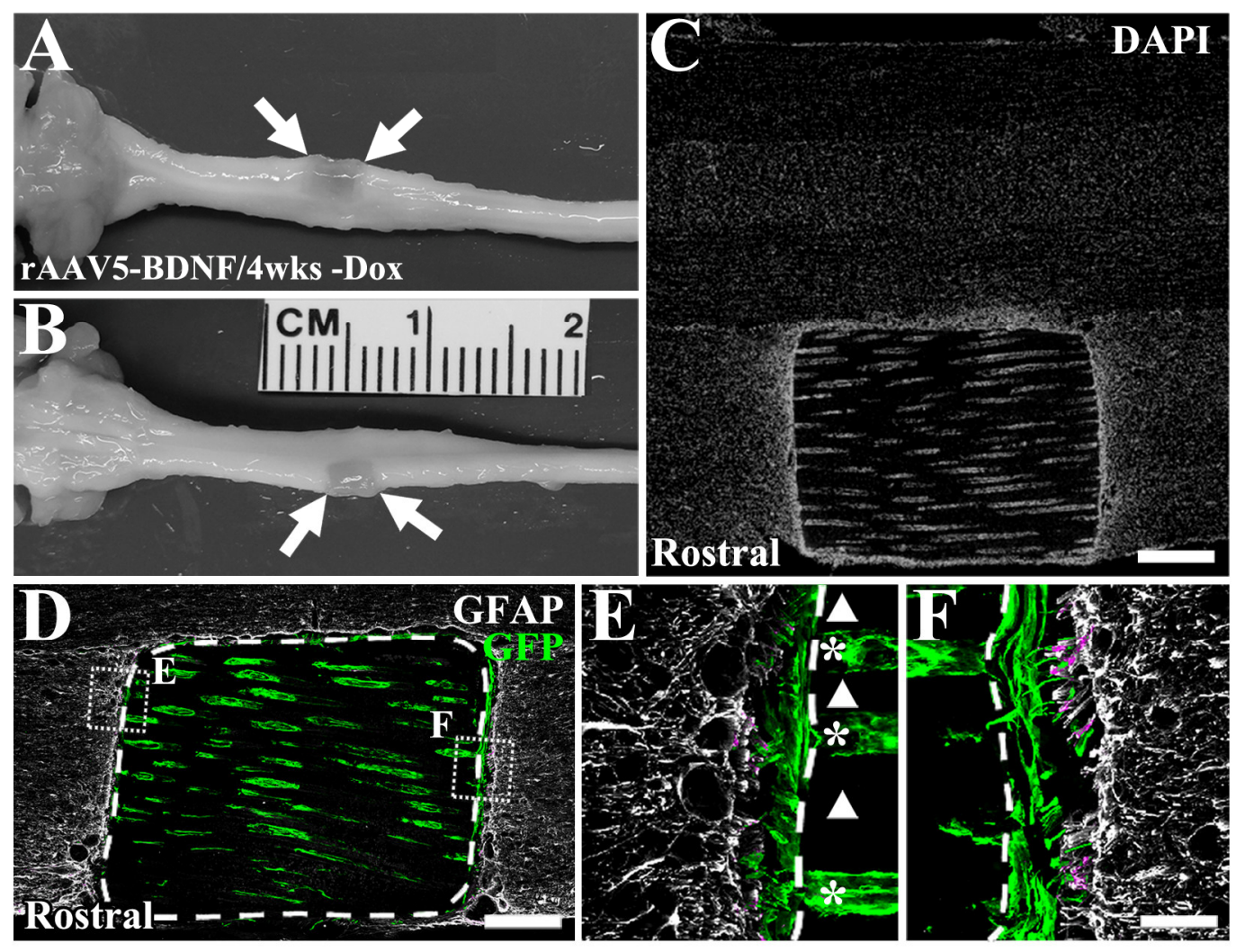

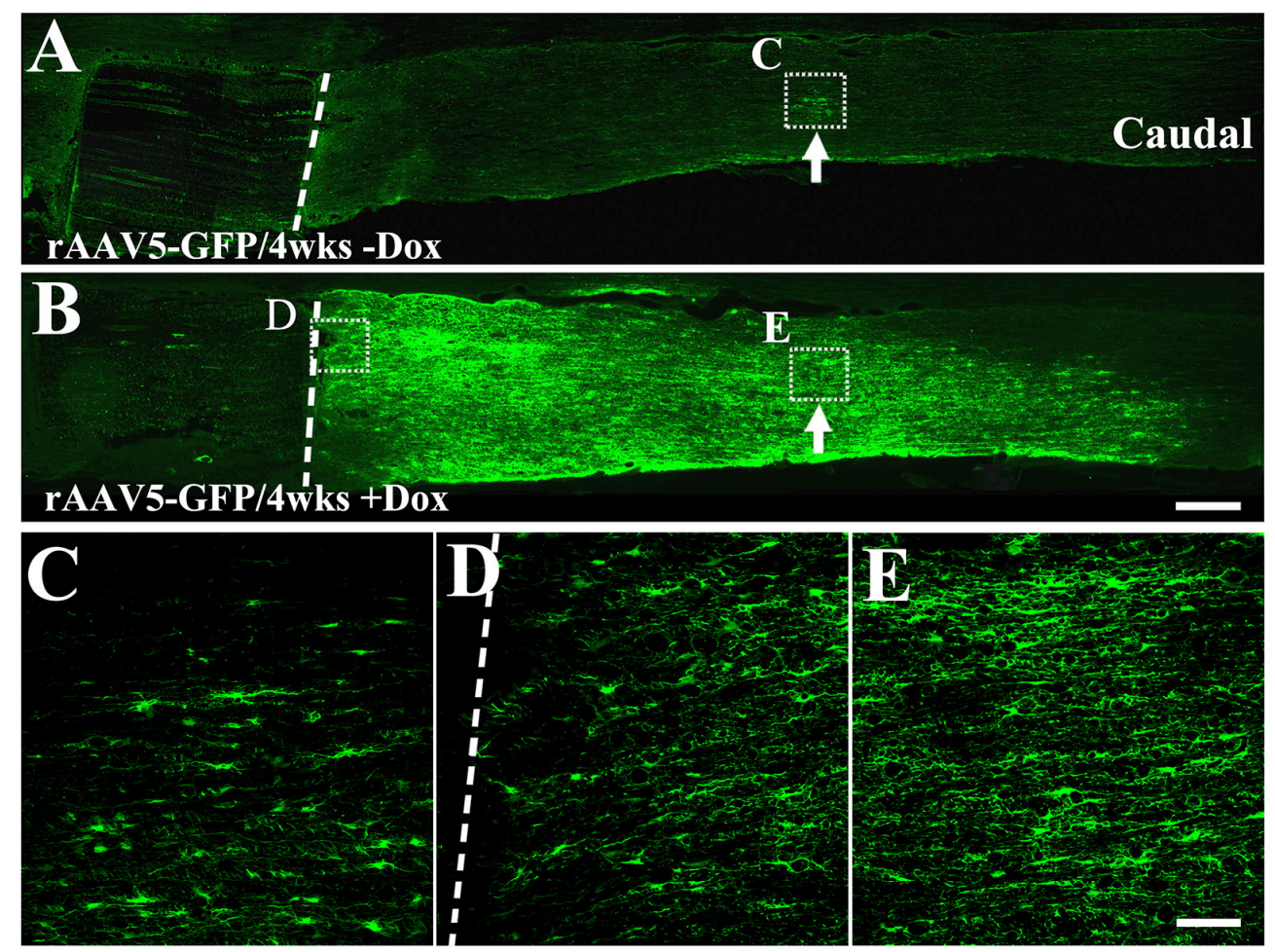

F

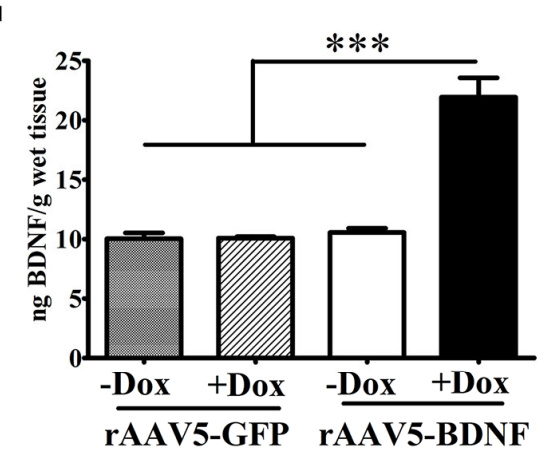

H

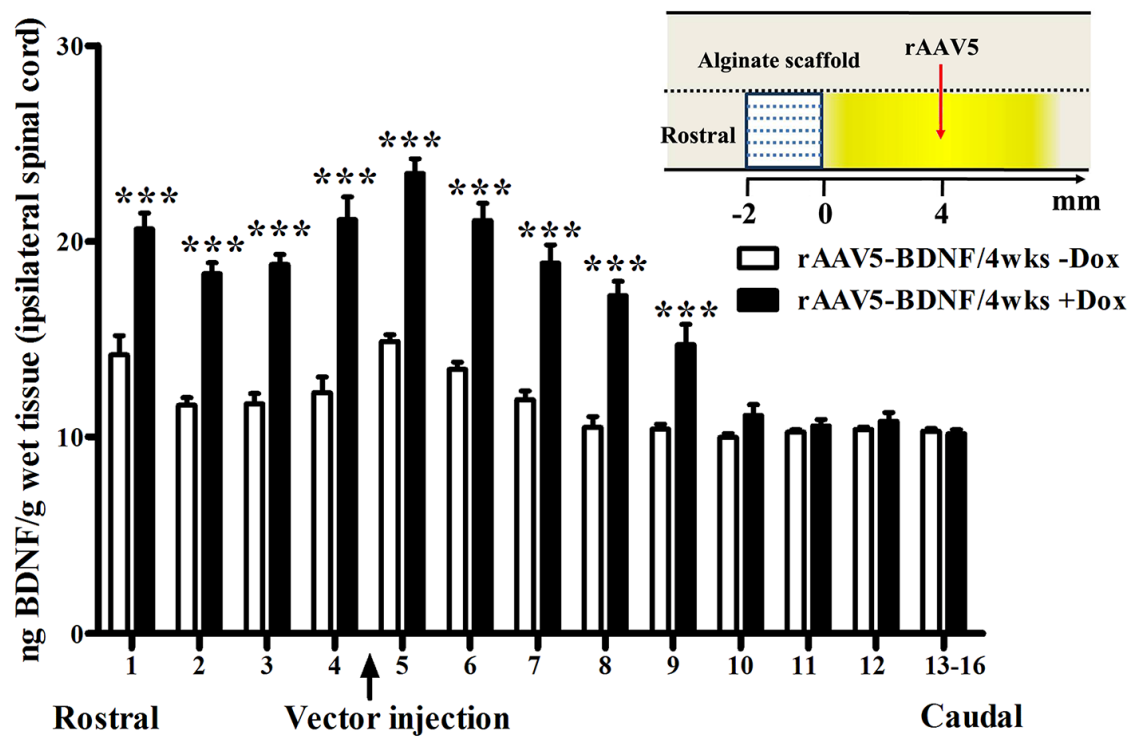

Distance (mm) from caudal host/graft interface 
Liu et al.

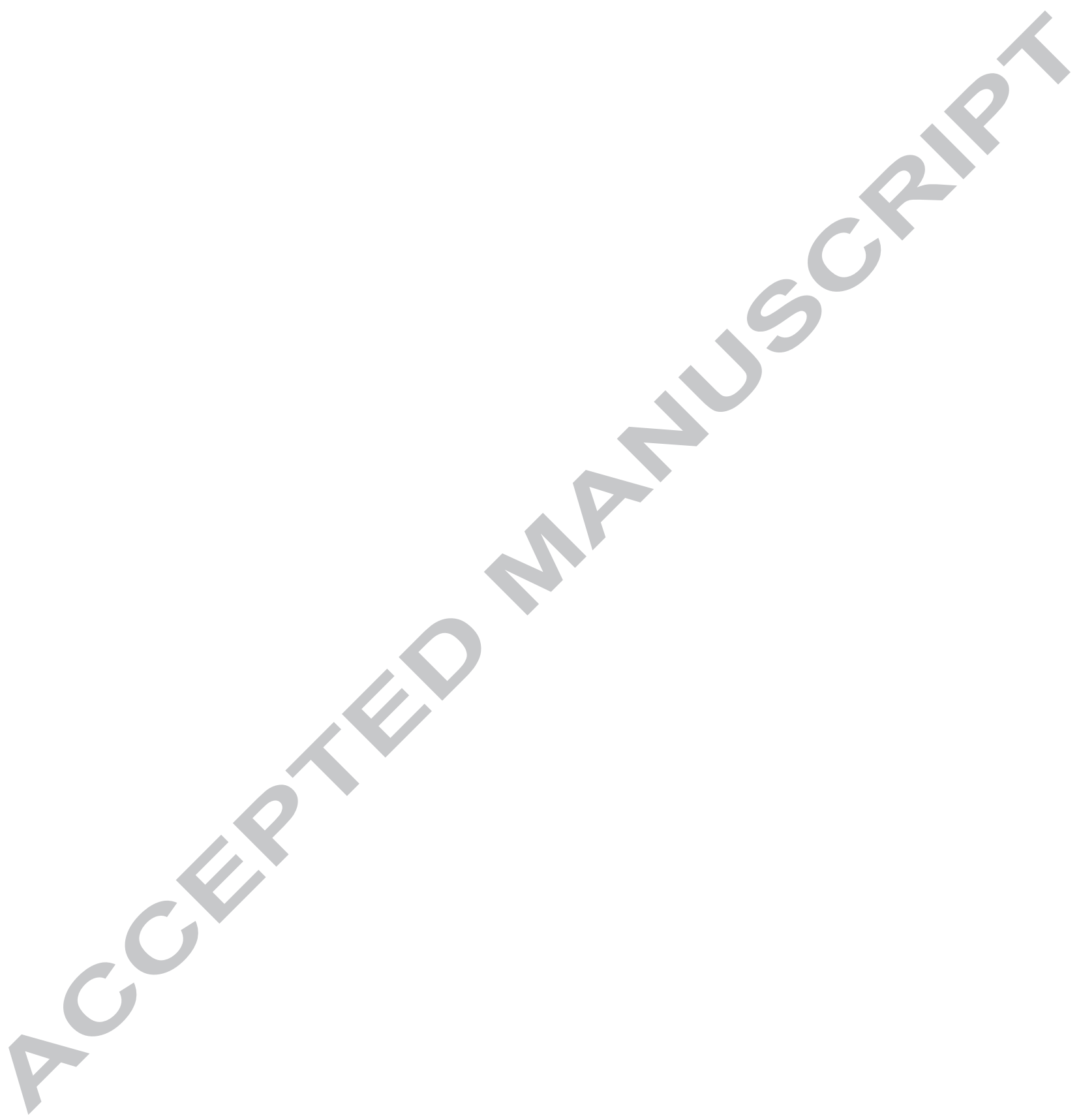



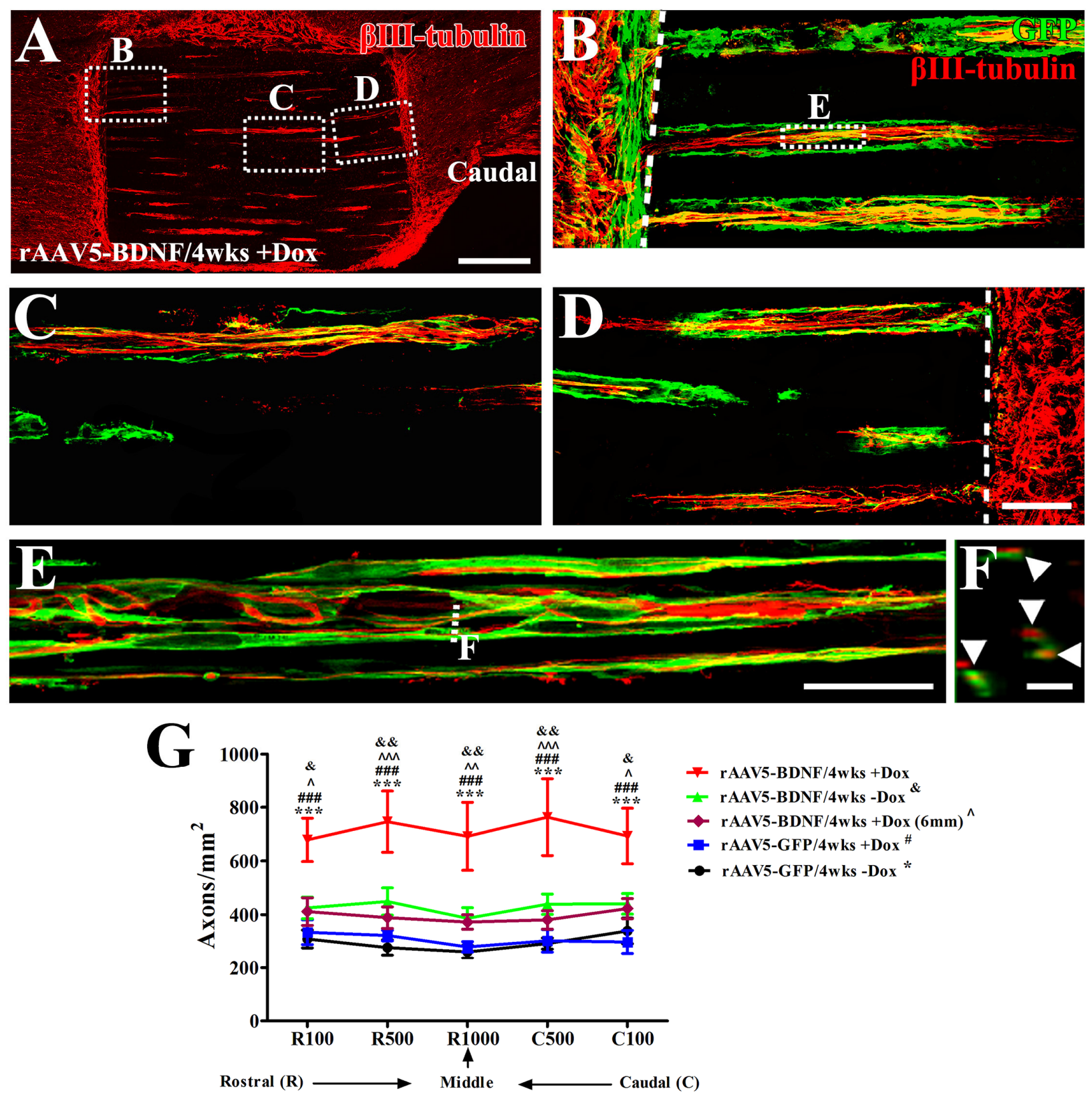

Distance $(\mu \mathrm{m})$ to the edge of the scaffold 


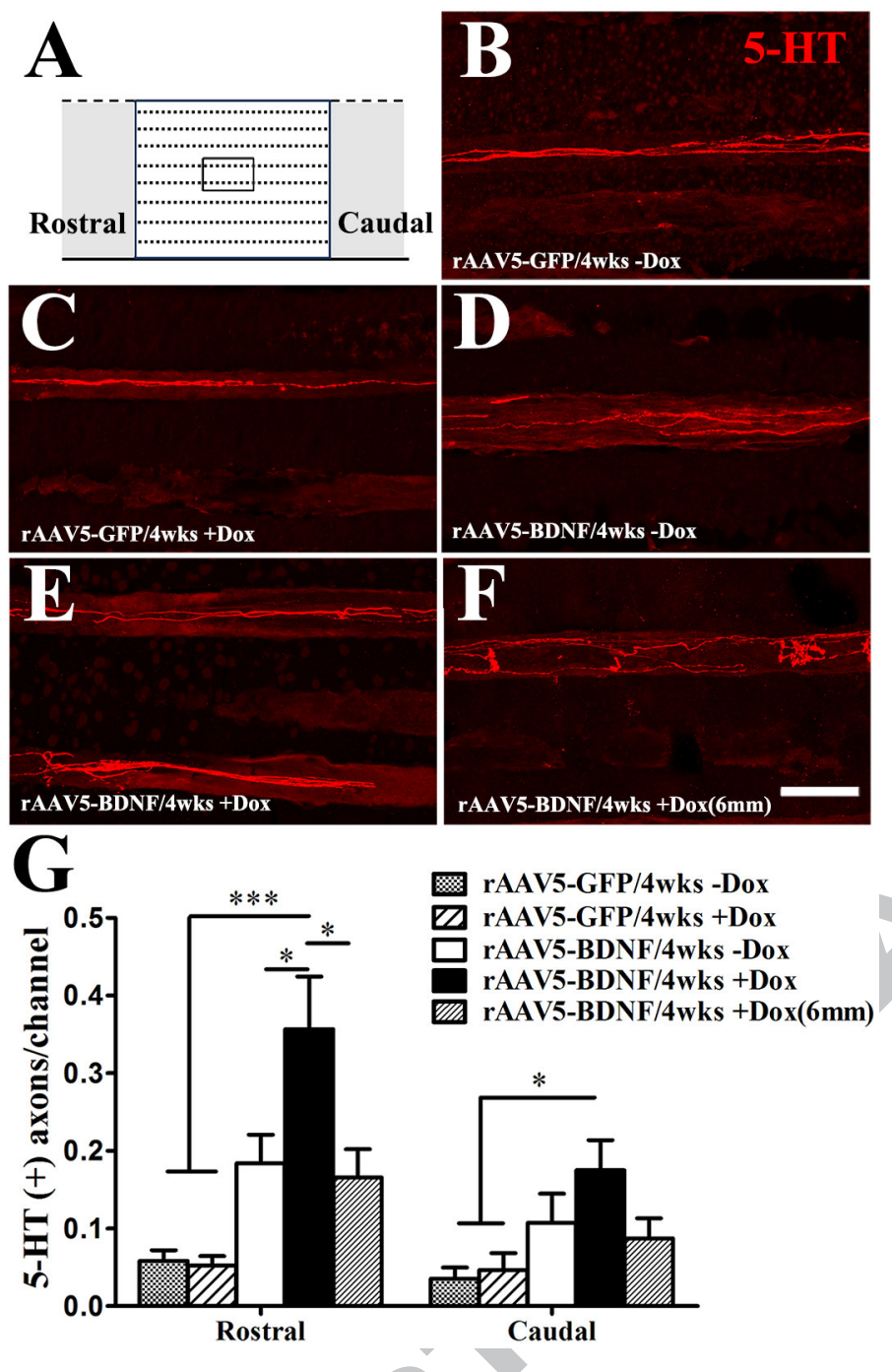




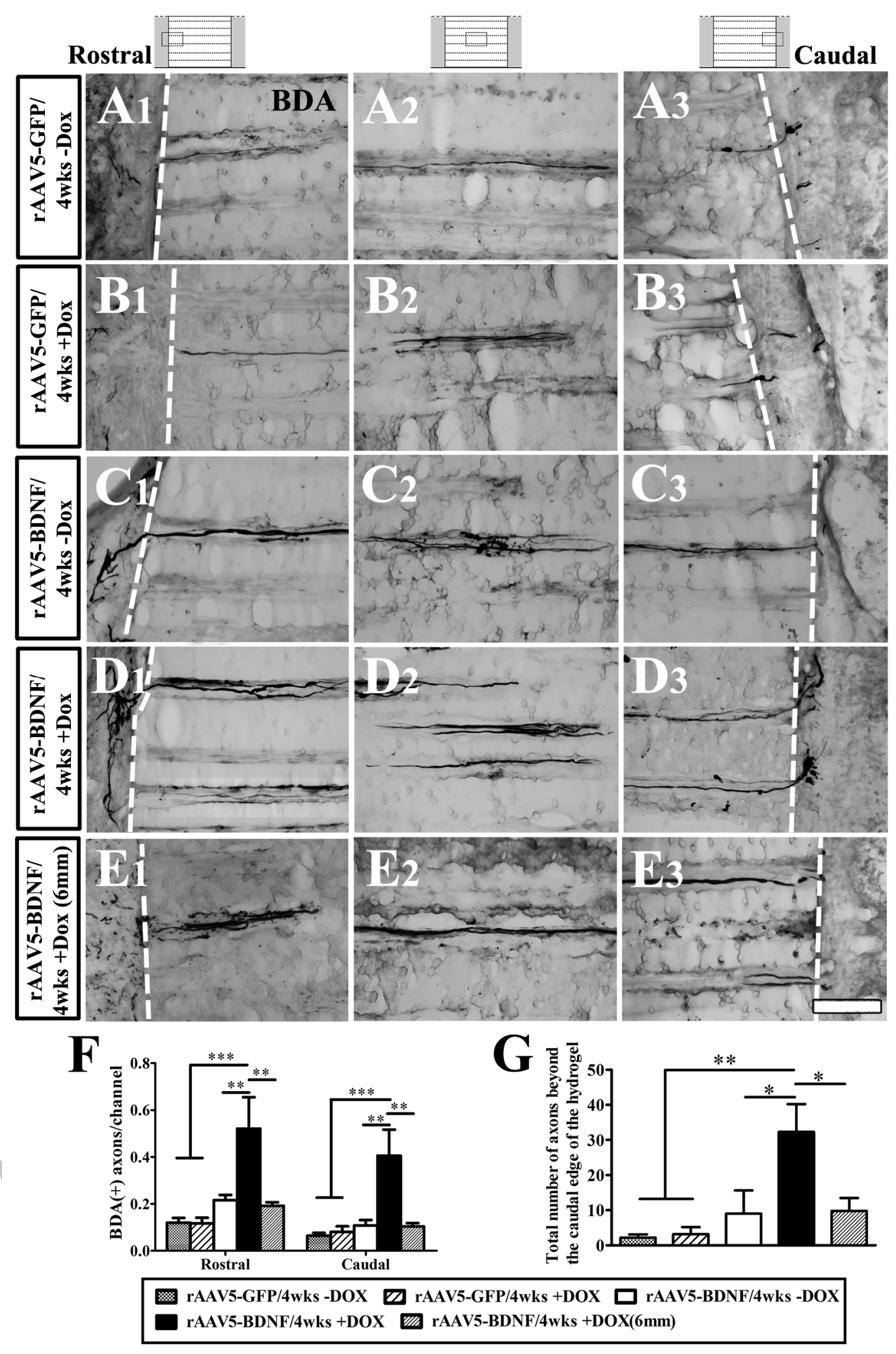




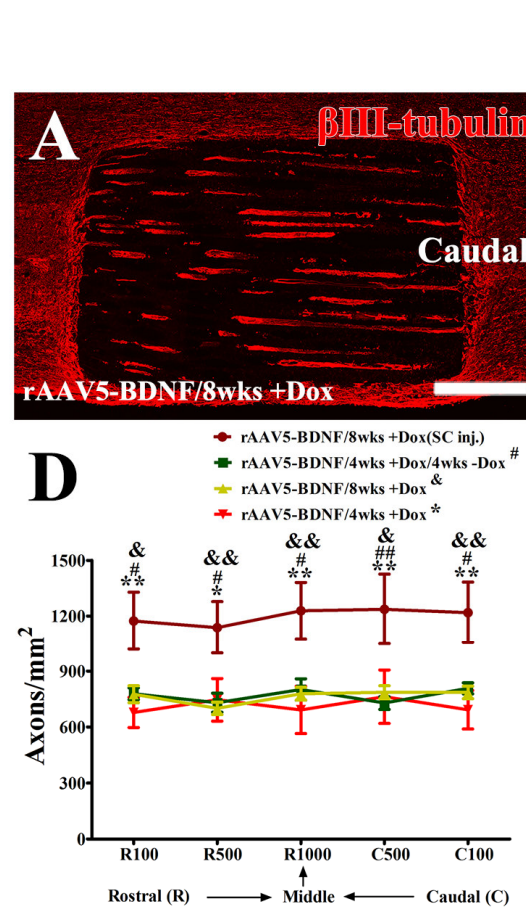

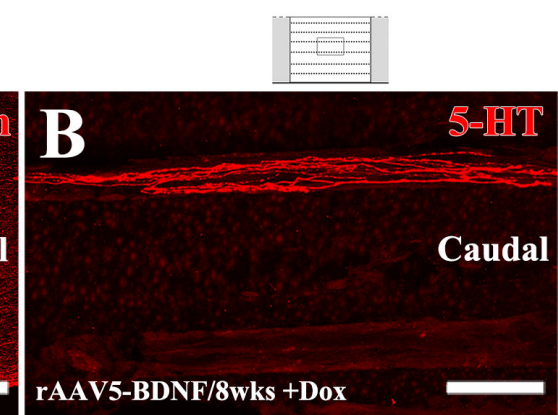

E

rAAV5-BDNF/4wks +Dox

rAAV5-BDNF/4wks +Dox/4wks -Dox

四 rAAV5-BDNF/8wks +Dox

rAAV5-BDNF/8wks + Dox(SC inj.)

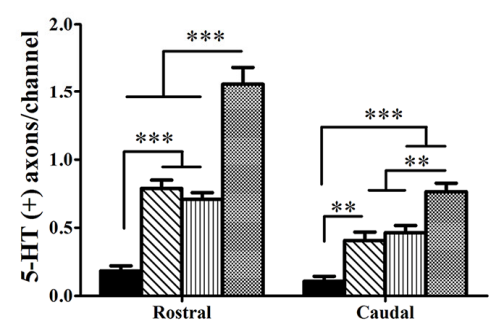

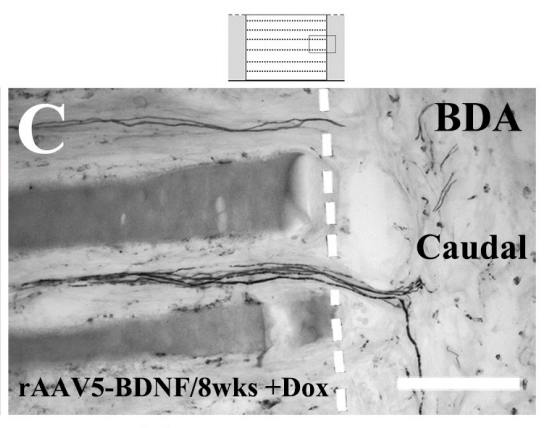

F

rAAV5-BDNF/4wks +Dox

$\checkmark$ rAAV5-BDNF/4wks +Dox/4wks -Dox

四 rAAV5-BDNF/8wks +Dox

rAAV5-BDNF/8wks +Dox(SC inj.)

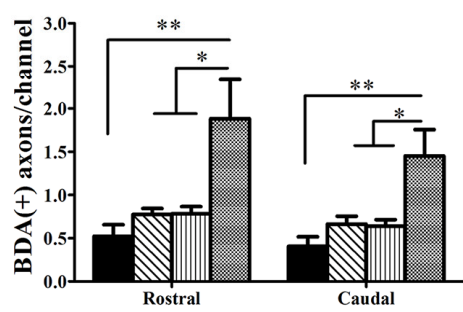

Distance $(\mu \mathrm{m})$ to the edge of the scaffold 
Liu et al.
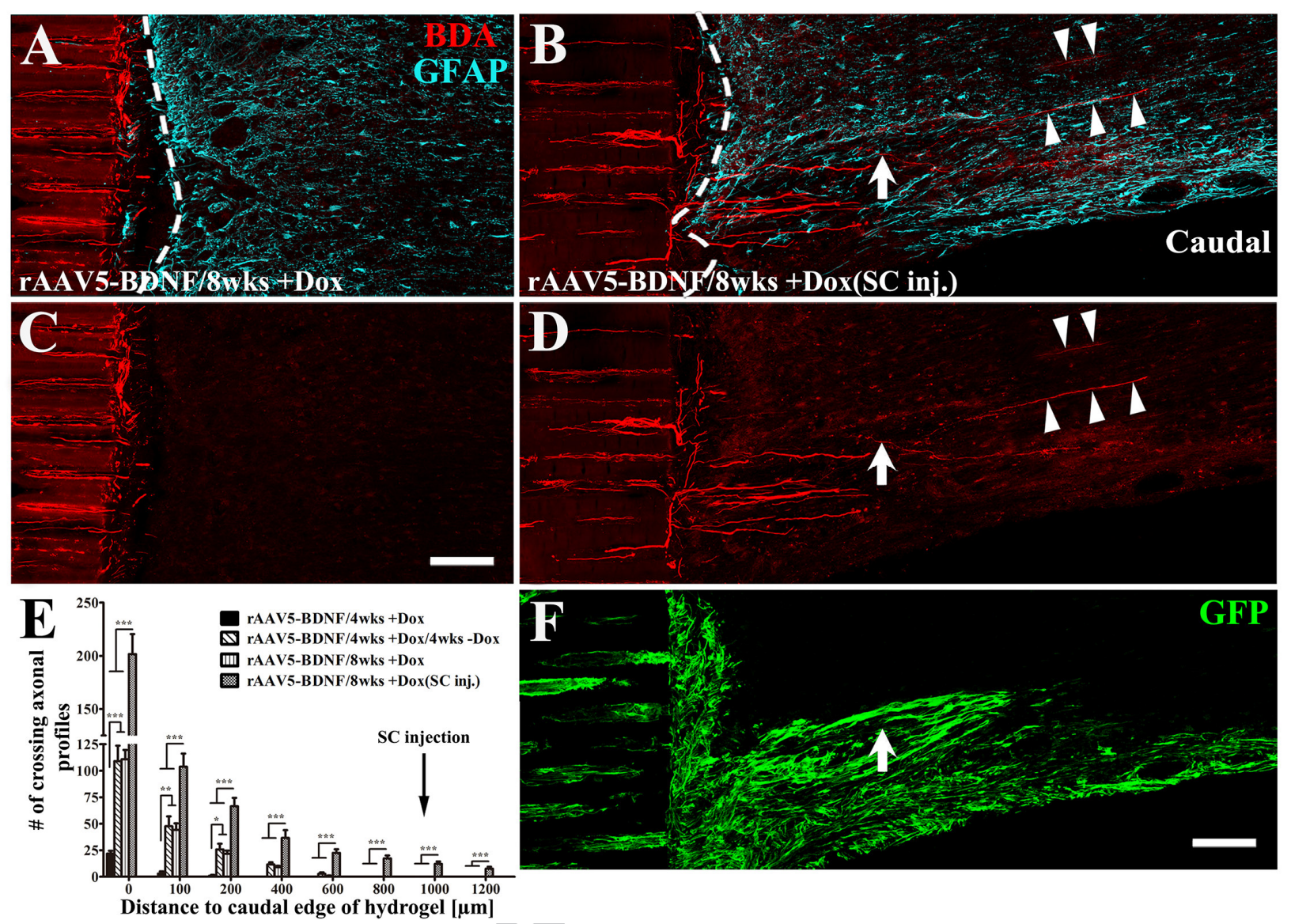
Liu et al.

Recovery from spinal cord injury is poor due to the limited regeneration observed in the adult mammalian central nervous system. Biomaterials, cell transplantation and growth factors that can guide axons across a lesion site, provide a cellular substrate, stimulate axon growth and have shown some promise in increasing the growth distance of regenerating axons. In the present study, we combined an alginate biomaterial with linear channels with transplantation of Schwann cells within and beyond the lesion site and injection of a regulatable vector for the transient expression of brain-derived neurotrophic factor (BDNF). Our data show that only with the full combination axons extend across the lesion site and that expression of BDNF beyond 4 weeks does not further increase the number of regenerating axons. 
Table 1: Experimental groups

\begin{tabular}{|c|c|c|c|c|c|}
\hline \multirow{2}{*}{$\begin{array}{l}\text { Gene } \\
\text { regulation }\end{array}$} & \multirow{2}{*}{ rAAV5 ${ }^{*}$} & \multirow{2}{*}{$\begin{array}{l}\text { SC seeding } \\
\text { in the } \\
\text { hydrogel }\end{array}$} & \multirow{2}{*}{$\begin{array}{c}\text { Caudal SC } \\
\text { injection }\end{array}$} & \multicolumn{2}{|c|}{ \# of animals } \\
\hline & & & & $\begin{array}{c}\text { Histological } \\
\text { analysis }\end{array}$ & $\begin{array}{l}\text { BDNF } \\
\text { ELISA }\end{array}$ \\
\hline 4 weeks on & BDNF & GFP-SC & - & 6 & 10 \\
\hline 4 weeks on & $\mathrm{BDNF}^{\S}(6 \mathrm{~mm})$ & WT-SC & - & 6 & \\
\hline 4 weeks off & BDNF & GFP-SC & - & 6 & 7 \\
\hline 4 weeks on & GFP & WT-SC & - & 6 & 3 \\
\hline 4 weeks off & GFP & WT-SC & - & 6 & 3 \\
\hline 8 weeks on & $\mathrm{BDNF}$ & WT-SC & GFP-SC & 6 & \\
\hline 8 weeks on & $\mathrm{BDNF}^{\S}$ & GFP-SC & - & 8 & \\
\hline $\begin{array}{l}4 \text { weeks on / } \\
4 \text { weeks off }\end{array}$ & $\mathrm{BDNF}^{\S}$ & WT-SC & - & 6 & \\
\hline
\end{tabular}

*Virus was injected in the host spinal cord tissue $4 \mathrm{~mm}$ caudal to the graft/host interface unless otherwise indicated.

${ }^{\S}$ Virus containing $10 \%(\mathrm{v} / \mathrm{v})$ rAAV5-GFP. 


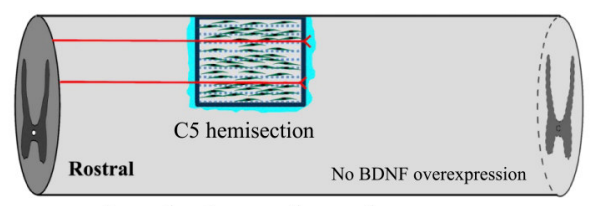

A-moderate axonal growth

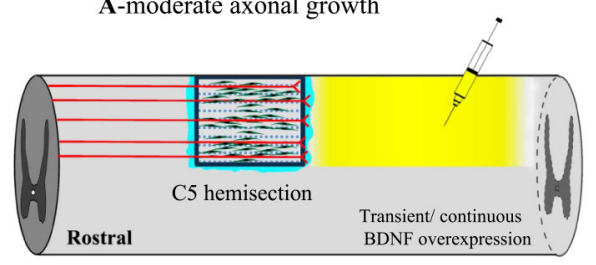

B-increased axonal growth approaching the interface

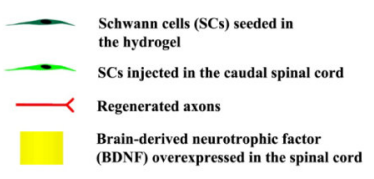

Alginate hydrogel with anisotropic

apillaries

Graft/host interface

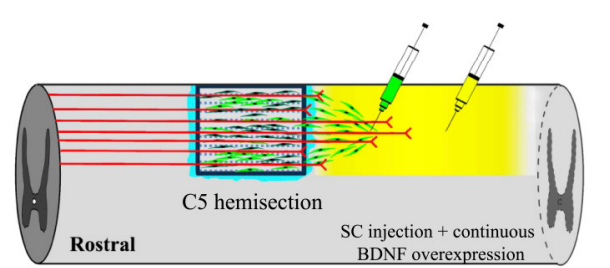

C-further increased axonal growth, extension beyond the interface along the injected $\mathrm{SCs}$ 